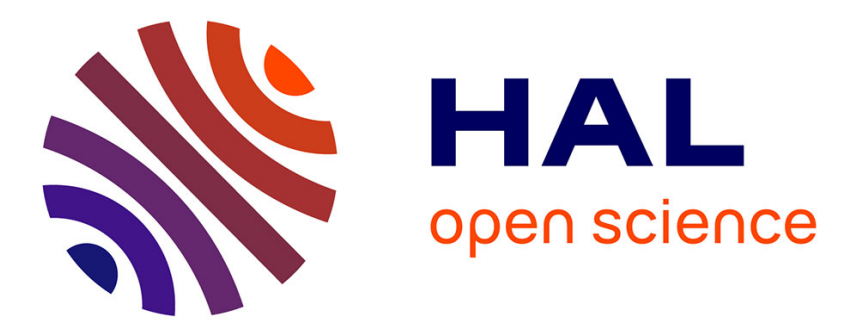

\title{
From powder to extrudate zeolite-based bifunctional hydroisomerization catalysts: zeolite integrity and Pt location
}

\author{
Pedro S.F. Mendes, João C. Silva, M. Filipa Ribeiro, Antoine Daudin, \\ Christophe Bouchy
}

\section{To cite this version:}

Pedro S.F. Mendes, João C. Silva, M. Filipa Ribeiro, Antoine Daudin, Christophe Bouchy. From powder to extrudate zeolite-based bifunctional hydroisomerization catalysts: zeolite integrity and Pt location. Journal of Industrial and Engineering Chemistry, 2018, 62, pp.72 - 83. 10.1016/j.jiec.2017.12.046 . hal-01894488

\section{HAL Id: hal-01894488 \\ https://hal-ifp.archives-ouvertes.fr/hal-01894488}

Submitted on 17 Oct 2018

HAL is a multi-disciplinary open access archive for the deposit and dissemination of scientific research documents, whether they are published or not. The documents may come from teaching and research institutions in France or abroad, or from public or private research centers.
L'archive ouverte pluridisciplinaire HAL, est destinée au dépôt et à la diffusion de documents scientifiques de niveau recherche, publiés ou non, émanant des établissements d'enseignement et de recherche français ou étrangers, des laboratoires publics ou privés. 


\section{From powder to extrudate zeolite-based bifunctional hydroisomerization catalysts: zeolite integrity and Pt location}

Pedro S. F. Mendes ${ }^{a, b}$, João M. Silva ${ }^{a, c}$, M. Filipa Ribeiro ${ }^{a}$, Antoine Daudin ${ }^{b}$, Christophe Bouchy ${ }^{b_{*}}$

${ }^{a}$ Centro de Química Estrutural, Instituto Superior Técnico, Universidade de Lisboa, Av. Rovisco Pais, 1049-001 Lisboa, Portugal

${ }^{b}$ IFP Energies nouvelles, Rond-point de l'échangeur de Solaize, BP 3, 69360 Solaize, France

${ }^{c} A D E Q-I S E L$, Instituto Superior de Engenharia de Lisboa, Instituto Politécnico de Lisboa, $R$. Cons. Emídio Navarro, 1959-007 Lisboa, Portugal

*christophe.bouchy@ifpen.fr ; +33(0)4 37702860

\section{Abstract}

The development of zeolite-based hydroisomerization catalysts in the powder form is widely spread in scientific literature but shaped bodies are the ones being employed in industry. This work aims at bridging that gap. The shaping procedure for HUSY zeolite in presence of an alumina binder disclosed herein achieved a full conservation of zeolite properties, e.g. porosity and Brønsted acidity. When Pt was located inside the zeolite and an homogeneous Pt distribution along the extrudate was ensured, shaped Pt-containing catalysts had similar hydroisomerization performances to those of powder Pt/zeolite in terms of turnover frequency per Brønsted acid site and maximal feed isomers yield. Conversely, non-uniform distribution of Pt along the extrudates diameter (macroscale) was observed to reduce the feed isomers yield. This was tentatively explained by the lower local metal to acid sites ratio in the core of the extrudates. Optimal performance of shaped bifunctional catalysts requires, hence, an adequate metal to acid sites ratio throughout the whole catalyst (i.e. at macroscale), even if full intimacy between catalytic functions is ensured at the nanoscale by the selective deposition of Pt inside the zeolite.

Keywords: hydroisomerization; zeolite shaping; HUSY; metal-acid balance; metal-acid intimacy 


\section{Introduction}

Bifunctional catalysts comprising acid and hydrogenation-dehydrogenation functions are of utmost important in industrial relevant processes. In the petroleum refining industry, the hydroisomerization of $\mathrm{C}_{5}-\mathrm{C}_{6} n$-paraffins to produce high-octane [1,2] gasoline and the production of diesel by hydrocracking of heavy oil cuts (e.g. vacuum gas oil) [1-4] is achieved thanks to bifunctional catalysts. In the context of diversification of liquid fuels sources, bifunctional catalysts have also a key role to play either on biodiesel production by hydrotreatment and hydroisomerization of vegetable oils [5-7] or synthetic diesel production by the Low Temperature Fischer-Tropsch process [8-11].

The hydroisomerization of long chain $n$-paraffins involves a bifunctional catalyst typically consisting of a noble metal finely dispersed over a zeolite (usually mixed with alumina). The choice of the adequate zeolite depends on acid-basic properties and on its pore architecture combining micro and mesopores [12,13]. The ultrastabilized Y (USY) zeolite is the most studied and industrially employed zeolite [3] but BEA zeolite [14-18] as well as some medium-pore frameworks have also revealed promising results [19-22]. For a given zeolite and operating conditions, the reaction rates are hence determined by the balance between the hydrogenatingdehydrogenating $(\mathrm{HDH})$ and acid functions [18,23,24], and the distance between these functions (Weisz's intimacy criterion) $[25,26]$. Specifically, most of the studies have shown that maximal intimacy between metal and acid sites enhances the selectivity in feed isomers $[25,26]$. However, recent reports reopened the debate about the ideal proximity between both functions for optimal performances [27]. Designing a bifunctional catalyst is thus a complex process where numerous parameters play a role requiring careful study. In order to reduce the degree of complexity, usually the studies on hydroisomerization catalysts are carried out over zeolitebased catalysts in the powder form. Consequently, studies focusing catalyst scale-up, and in particular shaped bifunctional catalysts, are lacking in open literature, in spite of the great number of patents in this field $[28,29]$.

In the case of zeolites, the most common method of shaping is mulling-extrusion method. This requires the use of a binder, typically alumina or silica, due to the very poor mechanical resistance of shaped zeolites [30]. Shaping is commonly described as a complex process during which the zeolite active sites can be drastically modified [31]. The existing reports focus on catalytic cracking catalysts and point out either beneficial or detrimental effects of shaping. The shaping of ZSM-5 zeolite with different binders, particularly boehmite, has been described to result in the neutralization of the most acidic Brønsted sites [32-35]. In the case of catalytic cracking, the reduction of the zeolite acidity can be beneficial conducing to a reduction of catalyst deactivation and so longer catalyst lifetimes $[32,33]$. Some cases of improved acidity following shaping processes are also documented in literature [35-38]. The characteristics of the binder and the shaping procedure play, hence, a vital role on the final properties of the 
zeolite [39], but for the same binder and shaping procedure different behaviours can also occur depending on the zeolite [40]. It is also worth mentioning that full preservation of the structure and porous network of zeolites can also be achieved but it is scarcely reported [41].

Up to now, the shaping process of zeolites and its impact on the behaviour of hydroisomerization catalysts has been scarcely considered in the open literature despite their industrial relevance. This work is a means of reducing this gap. Firstly, the properties of a HUSY zeolite will be studied throughout the scale-up, e.g. before and after shaping. The performances of a series of shaped bifunctional HUSY catalysts will be compared to that of powder HUSY ones in the hydroisomerization of $n$-hexadecane. Pt will be the hydrogenating function of both catalyst series. In order to compare the intrinsic behaviour of both catalysts, the metal to acid sites ratio will be varied while keeping, tentatively, a comparable metal-acid sites distance through the selective deposition of Pt particles inside the zeolite crystals.

\section{Materials and Methods}

\subsection{Catalysts preparation}

A commercial HUSY zeolite (CBV720) from Zeolyst, with a sodium to framework aluminium ratio of 0.01 , was employed without any further treatment. The shaped zeolite was prepared by a mulling-extrusion method. The binder used was a commercial boehmite (Pural SB-3) from Sasol which does not contain any cationic impurities. The zeolite, boehmite and Methocel powders (17:83:1 weight proportion on a dry basis) were mixed with an aqueous solution (57 $\mathrm{g}$ of water per $100 \mathrm{~g}$ of dry powder) containing $7.6 \mathrm{wt} . \%$ of nitric acid (i.e. $3.6 \mathrm{~g}$ of $\mathrm{HNO}_{3}$ per $100 \mathrm{~g}$ of dry boehmite). After kneading this mixture during $30 \mathrm{~min}$, an aqueous solution (59 $\mathrm{g}$ of water per $100 \mathrm{~g}$ of dry powder) containing $1 \mathrm{wt} . \%$ of ammonium was added. The kneading of the paste proceeded for $15 \mathrm{~min}$. The paste was extruded through a die having a trilobal shape with an diameter of $1.6 \mathrm{~mm}$. Extrudates were then dried at $353 \mathrm{~K}$ overnight and calcined at $873 \mathrm{~K}$ over 2

$\mathrm{h}$ (heating rate of $\left.5 \mathrm{~K} \mathrm{~min}^{-1}\right)$ under dry air $\left(1.5 \mathrm{NL} \mathrm{h}^{-1} \mathrm{~g}_{\text {support }}{ }^{-1}\right)$. The extrudates length was kept between 3 and $6 \mathrm{~mm}$. A reference sample containing only boehmite was prepared employing the same procedure in absence of zeolite.

The introduction of platinum in the unshaped zeolite was performed by incipient wetness impregnation of $\left[\mathrm{Pt}\left(\mathrm{NH}_{3}\right)_{4} \mathrm{NO}_{3}\right] \cdot 6 \mathrm{H}_{2} \mathrm{O}$ in a water solution. Aiming at a selective deposition of $\mathrm{Pt}$ in the zeolite crystals, the introduction of platinum in the shaped zeolite support was carried out by excess impregnation of the shaped zeolite with an aqueous solution containing [Pt $\left.\left(\mathrm{NH}_{3}\right)_{4} \mathrm{Cl}_{2}\right] \cdot \mathrm{H}_{2} \mathrm{O}$ and $\mathrm{NH}_{4} \mathrm{NO}_{3}$. The $\mathrm{NH}_{4} \mathrm{NO}_{3} / \mathrm{Pt}\left(\mathrm{NH}_{3}\right)_{4} \mathrm{Cl}_{2}$ molar ratio of 120 ensured the adequate $\mathrm{pH}$ in solution. Typically, 10 grams of shaped zeolite were immersed into $80 \mathrm{ml}$ of aqueous solution and gently stirred for $24 \mathrm{~h}$. Afterwards the extrudates were rinced with $160 \mathrm{ml}$ of distillated water. The same thermal treatments were performed for all materials. The impregnated materials were dried overnight at $383 \mathrm{~K}$ and then calcined in an air flow of $4 \mathrm{~L} \mathrm{~h}^{-1} \mathrm{~g}^{-}$ 
1. Three plateaux at 423,523 and $623 \mathrm{~K}$ over $1 \mathrm{~h}$ each and a final plateau at $773 \mathrm{~K}$ over $2 \mathrm{~h}$ were performed. A heating rate of $5 \mathrm{~K} \mathrm{~min}^{-1}$ was used.

\subsection{Solids characterization}

Quantitative elemental analysis was performed by x-ray fluorescence. Samples were grinded and sieved into a granulometry under $200 \mu \mathrm{m}$. Measurements were carried out directly over powder samples in a Thermofischer Scientific Advant- $X$ instrument. The identification of crystalline phases was achieved by $x$-ray powder diffraction (XRD). The diffraction patterns were acquired by a PANalytical X'Pert Pro diffractometer, in a Bragg-Brentano configuration with a stationary $\mathrm{x}$-ray source and a movable detector. The analysis range employed was from $2 \theta=2$ to $70^{\circ}$, with a step of $0,05^{\circ}$ and a counting time of 12 seconds per step. The XRD patterns were treated with the software EVA by Bruker and compared with database of ICDD (Figures S1 and S2).

Nitrogen adsorption measurements were carried out at $77 \mathrm{~K}$ on a Micrometrics ASAP 2010 apparatus. Before adsorption, zeolite samples were degassed under vacuum at $363 \mathrm{~K}$ for $1 \mathrm{~h}$ and then at $623 \mathrm{~K}$ for $4 \mathrm{~h}$. The total pore volume $\left(\mathrm{V}_{\text {total }}\right)$ was calculated from the adsorbed volume of nitrogen for a relative pressure $\mathrm{P} / \mathrm{P}_{0}$ of 0.97 whereas the microporous volume $\left(\mathrm{V}_{\text {micro }}\right)$ and surface area $\left(\mathrm{S}_{\text {micro }}\right)$ were determined using the $t$-plot method [42]. The mercury porosimetry was carried out in a Micrometrics Autopore IV 9500 apparatus under vacuum (30-50 mmHg). The sample was first pre-treated in a kiln at $523 \mathrm{~K}$ during $2 \mathrm{~h}$. The relationship between $\mathrm{Hg}$ pressure and pore diameter was obtained through the surface tension of mercury [43].

The size and morphology of the zeolite crystals in powder zeolite samples and in shaped zeolitic supports were studied by Scanning Electron Microscopy (SEM), using a SEM ZEISS Supra 40 equipped with a field emission gun and an Everhart-Thornley secondary electron detector. Local Si/Al ratios in zeolite crystals were measured by Energy Dispersive X-ray Spectrometry (TEM-EDX), in a JEOL JEM 2100F equipped with a Si-Li detector. Before observation, the powders were embedded in an epoxy resin and thin slices (about $70 \mathrm{~nm}$ ) were cut by ultramicrotomy and transferred onto a copper grid covered by a holey carbon membrane.

Platinum dispersion of shaped supports was determined by oxygen titration of chemisorbed hydrogen in a homemade apparatus with a thermal conductivity detector. The pre-reduced saturated samples were pre-treated under $\mathrm{H}_{2}$. Two cycles of hydrogen titration of chemisorbed oxygen and oxygen titration of chemisorbed hydrogen were consecutively performed at room temperature. The results presented correspond to the average $\mathrm{O}_{2}$ consumption in the two cycles; relative deviation between measures was inferior to $10 \%$. The metal dispersion was calculated by means of a $0.75 \mathrm{O}_{2}$ :Pt stoichiometric coefficient $[44,45]$. 
The investigation of metal location implies the use of microscopic techniques. For powder samples, the most comprehensive technique is electron tomography which enables a 3dimensional visualization of the zeolite crystals exceeding thus the 2-dimension information routinely obtained by transmission electron microscopy. For Pt/HUSY samples in particular, electron tomography measurements revealed a homogeneous distribution of $\mathrm{Pt}$ inside the zeolite crystals [46]. In the case of shaped materials, the lack of studies in literature goes along with underdeveloped analytical tools for the study of such materials. Techniques that have been successfully used to assess the location of elements in shaped materials is the electron probe micro analysis (EPMA) and TEM-EDX [47]. For noble metals at low concentration, TEM-EDX is not sensitive enough to detect the metal in the zeolite and in the binder. Despite its lower spatial resolution, the sensitivity of EPMA allows to extrapolate the concentration of metal in binder and zeolithe.

The electron probe micro analysis (EPMA) were carried out in a JEOL JXA 8100 equipment. The extrudates were embedded in an Specifix-40 epoxy resin (Struers, Ballerup) that was prepolymerized to prevent carbon contamination [48] and polished to obtain a flat section. A thin conductive carbon layer was deposited to prevent surface charging effects. Samples were analysed using a $20 \mathrm{keV}$ and $100 \mathrm{nA}$ electron beam. Al was analysed on the $\mathrm{K} \alpha$ (2) line, Si on the $\mathrm{K} \alpha$ line, $\mathrm{Pt}$ on the $\mathrm{M} \alpha$ line and $\mathrm{O}$ was calculated assuming $\mathrm{Al}_{2} \mathrm{O}_{3}$ and in $\mathrm{SiO}_{2}$ stoichiometry. For each sample, five profiles were measured on five different catalyst grains along a 3-fold symmetry axis of the extrudates (from a hollow to the lobe), further called the diameter in the paper. Each profile was acquired with 25 points resulting in a constant step of about $56 \mu \mathrm{m}$. Local measured concentrations were then processed using the method of the distance transform [49] to obtain the overall concentration of each element in the extrudate.

In order to condense the elemental profiles into a single parameter, a distribution coefficient can be used. The distribution coefficient $R_{\text {element }}$ is the ratio of the mean concentration along the extrudate to overall concentration assuming a spherical grain of diameter $2 r$ equal to the length of the profile [50] (Eq. 1). By these means, a distribution coefficient close to 1 means a uniform distribution of the element along the extrudate diameter. Otherwise, the coefficient will be higher than 1 , if the concentration is greater in the core than at the edges (so-called egg-yolk distribution); and lower than 1 if the concentration is greater at the edges than in the core (socalled egg-shell distribution) [50].

To calculate the concentration of Pt in alumina and zeolite phases, the approach described by Kasztelan et al. was applied [47]. For all the analysis points in all the extrudates EPMA gave $c_{\mathrm{Al}_{2} \mathrm{O}_{3}}$ the local concentration in $\mathrm{Al}_{2} \mathrm{O}_{3}$ and $c_{\mathrm{SiO}_{2}}$ the local concentration in $\mathrm{SiO}_{2}$. Knowing the weight ratio $y=c_{\mathrm{Si}_{2}} / c_{\mathrm{Al}_{2} \mathrm{O}_{3}}=20.4$ of the zeolite, we calculated on each analysis point the local concentration in alumina phase $c_{\text {alumina }}=c_{\mathrm{Al}_{2} \mathrm{O}_{3}}-y^{-1} c_{\mathrm{SiO}_{2}}$, and in zeolite phase $c_{\text {zeolite }}=$ 
$c_{\mathrm{SiO}_{2}}\left(1+y^{-1}\right)$. The corresponding zeolite local weight fraction of supports $x_{\text {zeolite }}$ was then calculated using Eq. 2.

$$
\begin{array}{cr}
R_{\text {element }}=\frac{r^{2} \int_{-r}^{r} C_{\text {element }}(x) d x}{3 \int_{-r}^{r} C_{\text {element }}(x) x^{2} d x} & \text { Equation 1 } \\
x_{\text {zeolite }}=\frac{c_{\mathrm{SiO}_{2}}\left(1+y^{-1}\right)}{c_{\mathrm{Si}_{2}}+c_{\mathrm{Al}_{2} \mathrm{O}_{3}}} & \text { Equation 2 }
\end{array}
$$

The plot of $c_{\mathrm{Pt}}$, the local concentration of $\mathrm{Pt}$, as function of $x_{\text {zeolite }}$ was fitted to a straight line. Extrapolation of the line for $x_{\text {zeolite }}=0$ and for $x_{\text {zeolite }}=1$ gave the concentrations of Pt on the alumina phase and zeolite phase respectively.

Details on the characterization of Pt/HUSY samples can be found elsewhere in literature $[46,51]$.

\subsection{Catalytic tests}

The m-xylene isomerization was used as a model reaction to characterize the Brønsted acidity of zeolite and alumina-shaped zeolite. The reaction was carried out at $623 \mathrm{~K}$ under atmospheric pressure using a pyrex glass down-flow reactor. All catalysts were tested at the same granulometry $(0.2-0.5 \mathrm{~mm})$. Shaped samples were grinded into $0.2-0.5 \mathrm{~mm}$ pellets whereas powder samples were first pressed into wafers $\left(\rho_{\text {wafer }}=10 \mathrm{mg} \mathrm{cm}^{-2}\right)$ and then grinded. Before reaction, samples were pre-treated under air flow $\left(150 \mathrm{NL} \mathrm{h}^{-1} \mathrm{~g}_{\text {zeolite }}{ }^{-1}\right)$ at $623 \mathrm{~K}$ over $4 \mathrm{~h}$ (heating rate of $5 \mathrm{~K} \mathrm{~min}^{-1}$ ). Reaction took place under nitrogen flow (160 NL h $\mathrm{h}^{-1} \mathrm{~g}_{\text {zeolite }}{ }^{-1}$ ), using a weight hourly space velocity of $5.6 \mathrm{~g}_{\mathrm{m} \text {-xylene }} \mathrm{g}_{\text {zeolite }}{ }^{-1} \mathrm{~s}^{-1}$. This space velocity ensured conversion levels below $20 \%$ for all catalysts. The reactor effluent was heated at about $413 \mathrm{~K}$ to prevent product condensation and was analysed on-line in an apparatus for gas-chromatography coupled with a flame ionization detector (GC-FID) equipped with a $50 \mathrm{~m}$ HP-FFAP capillary column from Agilent. An analysis was performed at every $20 \mathrm{~min}$. At each time, the catalytic activity was calculated as the amount of m-xylene converted per zeolite mass and per unit of time. The deactivation curve (i.e. catalytic activity vs. time-on-stream) was fitted to a logarithmic equation and the activity at $1 \mathrm{~min}$ of reaction was extrapolated by means of such equation.

The hydroisomerization of $n$-hexadecane took place in high-throughput catalytic test unit with fixed-bed downflow reactors described elsewhere [52]. The catalytic testing was fully automated, with the operating conditions of the catalytic bed of each reaction being monitored individually. As for $m$-xylene isomerization, all catalysts were tested at the same granulometry (0.2-0.5 mm) in order to prevent any diffusional limitations. The catalyst was then pre-treated using a hydrogen flow rate of $4 \mathrm{NL} / \mathrm{h} / \mathrm{g}$ and heated at $5 \mathrm{~K} / \mathrm{min}$ to a final reduction temperature of $723 \mathrm{~K}$ for one hour. The tests were performed at $1.1 \mathrm{MPa}$ total pressure, a molar $\mathrm{H}_{2}$ to $n-\mathrm{C}_{16}$ 
ratio of 10 . The weight hourly space velocity (WHSV) ranged between 0.14 and $1.1 \mathrm{mg}_{n \text {-hexadecane }}$ $g_{\text {catalyst }}{ }^{-1} \mathrm{~s}^{-1}$ and the reaction temperature ranged from 483 to $498 \mathrm{~K}$ in order to modify the conversion level. Products were analysed on-line by a GC-FID apparatus equipped with low polarity capillary columns from Agilent (DB-1 and CP-Sil-5-CB). Deactivation of all samples was negligible at the end of the catalytic tests. Catalytic performances were calculated by mass balance to the carbon atoms at the outlet. $\mathrm{n}-\mathrm{C}_{16}$ conversion was calculated as the amount of carbon atoms of the products divided by total amount of carbon atoms (uncertainty $\pm 5 \%$ for conversion). The yield of a given product was calculated as the amount of carbon atoms of that product divided by total amount of carbon atoms (uncertainty $\pm 2 \%$ for $\mathrm{i}-\mathrm{C}_{16}$ yield). Activity was calculated as the apparent kinetic constant for first-order consumption of $n$-hexadecane per catalyst mass per unit of time. The average turnover frequency per Brønsted sites was defined as the activity per mole of Bronsted acid site of the zeolite, $\mathrm{Al}^{\mathrm{IV}}$ (see Table 1).

\section{Results}

\subsection{Characterization of the supports}

\section{Physico-chemical properties}

The samples were firstly characterized by Scanning Electron Microscopy (SEM) to get hold of the extrudates macroscopic organization. The micrographs for shaped HUSY extrudates are depicted in Figure 1. The shaped support consisted in a dense and homogeneous matrix presenting a number of morphological features (Figure 1a). The main population was composed of assemblies of some well-defined crystals dispersed in a homogeneous way in the support (Figure 1c). Porous clusters of crystals in the 1-20 $\mu \mathrm{m}$ size range were also detected (Figure 1b). Crystals were in the $300-1000 \mathrm{~nm}$ range matching that observed for parent zeolite [46]. The white spots correspond to dense agglomerates of HUSY crystals (Figure 1d). These agglomerates were also observed in parent zeolite (Figure S3) and, according to TEM-EDX have a Si/Al atomic ratio (3.5) to that typically attained in as-synthesized $Y$ zeolite (2.1-3.0) [53]. Therefore, the dense particles observed should correspond to $Y$ zeolite that did not undergo any subsequent post-treatments. For the main population of HUSY crystals, a Si/Al atomic ratio of 18.6 was measured. This composition is analogous to that of the bulk sample (16.7), determined by X-Ray Fluorescence (Table 1), confirming that the dense particles observed were minor in the HUSY sample. 

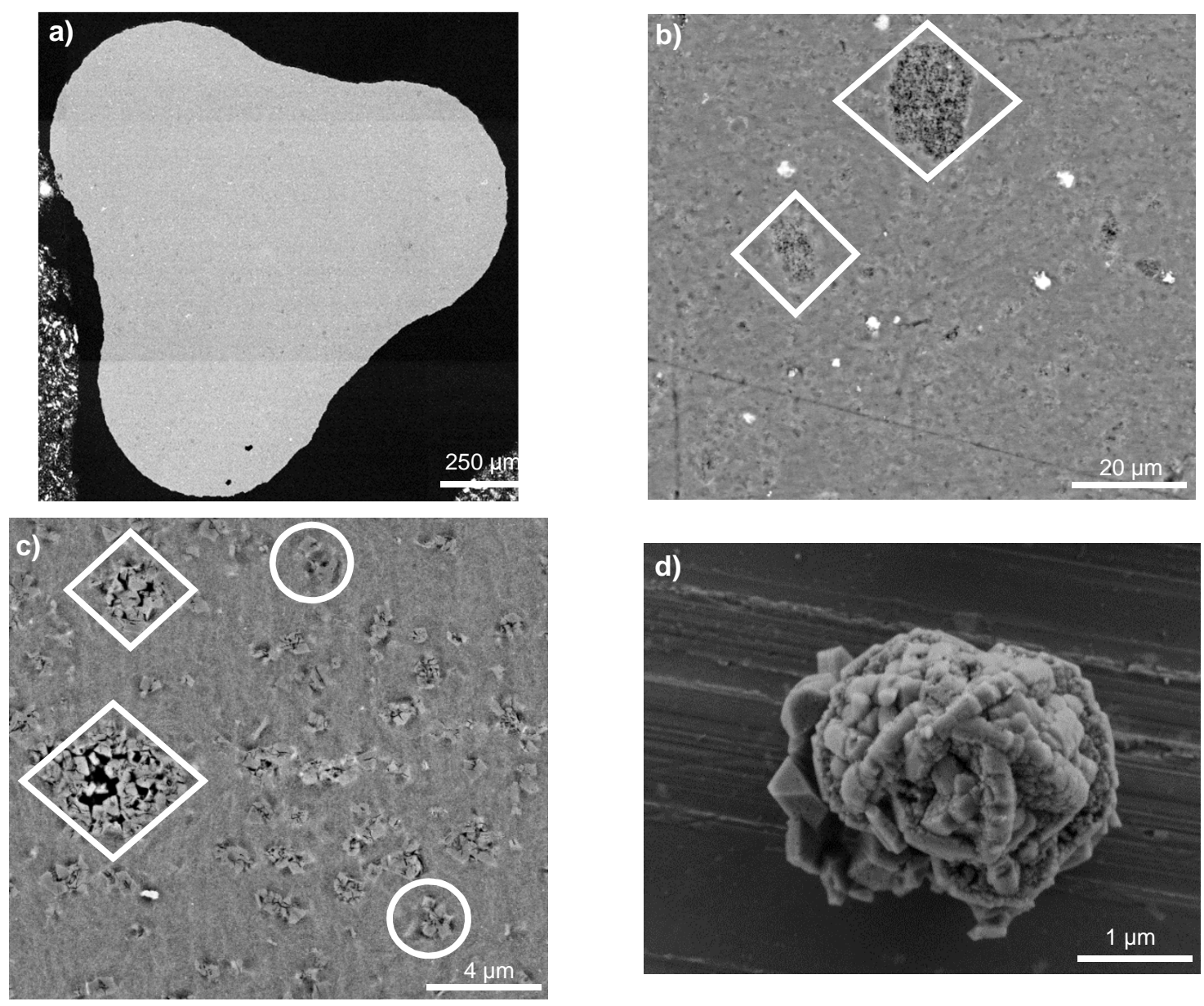

Figure 1: a), b), c) SEM micrographs for HUSY extrudates after a),b) mechanical polishing, and c) ionic cross section polishing (diamonds denote porous clusters of HUSY crystals and circles denote small aggregates of zeolite). d) SEM micrograph for a dense HUSY zeolite agglomerate (direct observation from HUSY sample).

The physico-chemical properties of the HUSY zeolite as well as the shaped extrudates are presented in Table 1. The commercial HUSY ((atomic Si/AI) $\left.)_{\text {global }}=16.7\right)$ sample employed herein has been previously characterized in detail [46,51]. The diffractogram disclosed a purely crystalline zeolite (Figure 2) with the typical diffraction pattern of FAU framework. In terms of pore topology, FAU framework has a 3-dimensional channel with an equivalent minimum pore size of $0.74 \mathrm{~nm}$ and supercages of $1.4 \mathrm{~nm}$ in the channel intersections [54]. The framework $\mathrm{Si} / \mathrm{Al}$ atomic ratio amounted to 18.4 , resulting in a concentration of framework aluminium $\mathrm{Al}^{\mathrm{IV}}$ of $820 \mu \mathrm{mol} \mathrm{g}{ }^{-1}$ [51]. As these aluminium atoms generate negatively charged oxygen atoms in zeolites framework [1], $\mathrm{n}_{\mathrm{Al}(\mathrm{IV})}$ is an estimation of Brønsted acid sites concentration for zeolites in the protonic form.

Table 1: Zeolite fraction, $\mathrm{Al}^{\mathrm{IV}}$ concentration, micro and mesopores properties by $\mathrm{N}_{2}$ adsorptiondesorption, and macropores properties by $\mathrm{Hg}$ porosimetry for supports.

\begin{tabular}{|c|c|c|c|c|c|c|c|c|}
\hline Sample & $\begin{array}{c}\mathrm{Si}^{\mathrm{a}} \\
\text { (wt.\%) }\end{array}$ & $\begin{array}{c}\text { Zeolite } \\
\text { (wt.\%) }\end{array}$ & $\frac{n_{\mathrm{Al}(\mathrm{IV})}}{\left(\mu \mathrm{mol} \mathbf{g}^{-1}\right)}$ & $\begin{array}{c}V_{\text {micro }} \\
\left(\mathrm{mL} \mathrm{g}^{-1}\right)\end{array}$ & $\begin{array}{c}S_{\text {micro }} \\
\left(\mathrm{m}^{2} \mathrm{~g}^{-1}\right)\end{array}$ & $\begin{array}{c}V_{\text {meso }} \\
\left(\mathrm{mL} \mathrm{g}^{-1}\right)\end{array}$ & $\begin{array}{c}S_{\text {meso }} \\
\left(\mathrm{m}^{2} \mathrm{~g}^{-1}\right)\end{array}$ & $\begin{array}{c}V_{\text {macro }} \\
\left(\mathrm{mL} \mathrm{g}^{-1}\right)\end{array}$ \\
\hline HUSY & 43.9 & 100 & 820 & 0.33 & 813 & 0.21 & 101 & n.d. \\
\hline $\mathrm{Al}_{2} \mathrm{O}_{3}$ & - & - & - & n.d. & n.d. & 0.62 & 263 & n.d. \\
\hline
\end{tabular}




\begin{tabular}{|c|c|c|c|c|c|c|c|c|}
\hline $\mathrm{Al}_{2} \mathrm{O}_{3}+\mathrm{HUSY}$ & 7.3 & $16.5^{b}$ & $135^{\mathrm{c}}$ & 0.045 & 105 & 0.59 & 266 & n.d. \\
\hline
\end{tabular}

The trilobe extrudates were characterized after calcination. The only phase detected in the shaped support based exclusively on binder matched with $\mathrm{y}-\mathrm{Al}_{2} \mathrm{O}_{3}$ transition phase (Figure 2). This phase is known to occur after calcination of boehmite in the $773-1073 \mathrm{~K}$ range [55]. This result was thus in agreement with the calcination temperature of the support (873 K). The diffractograms of HUSY, alumina, and shaped HUSY (Figure 2) only revealed $\mathrm{Y}-\mathrm{Al}_{2} \mathrm{O}_{3}$ and $\mathrm{FAU}$ framework phases. Moreover, the width of the peaks was similar pointing to a comparable level of crystallinity in both parent HUSY and shaped HUSY samples. The fraction of zeolite in the $\mathrm{Al}_{2} \mathrm{O}_{3}+\mathrm{HUSY}$ sample was thus estimated based on the amount of silicon detected (Table 1). The zeolitic extrudate comprised roughly $83.5 \%$ of alumina and $16.5 \%$ of HUSY zeolite. Accordingly, the concentration of $\mathrm{Al}^{\mathrm{IV}}$ sites in the extrudate is expected to be around $135 \mu \mathrm{mol} \mathrm{g}^{-}$ 1.

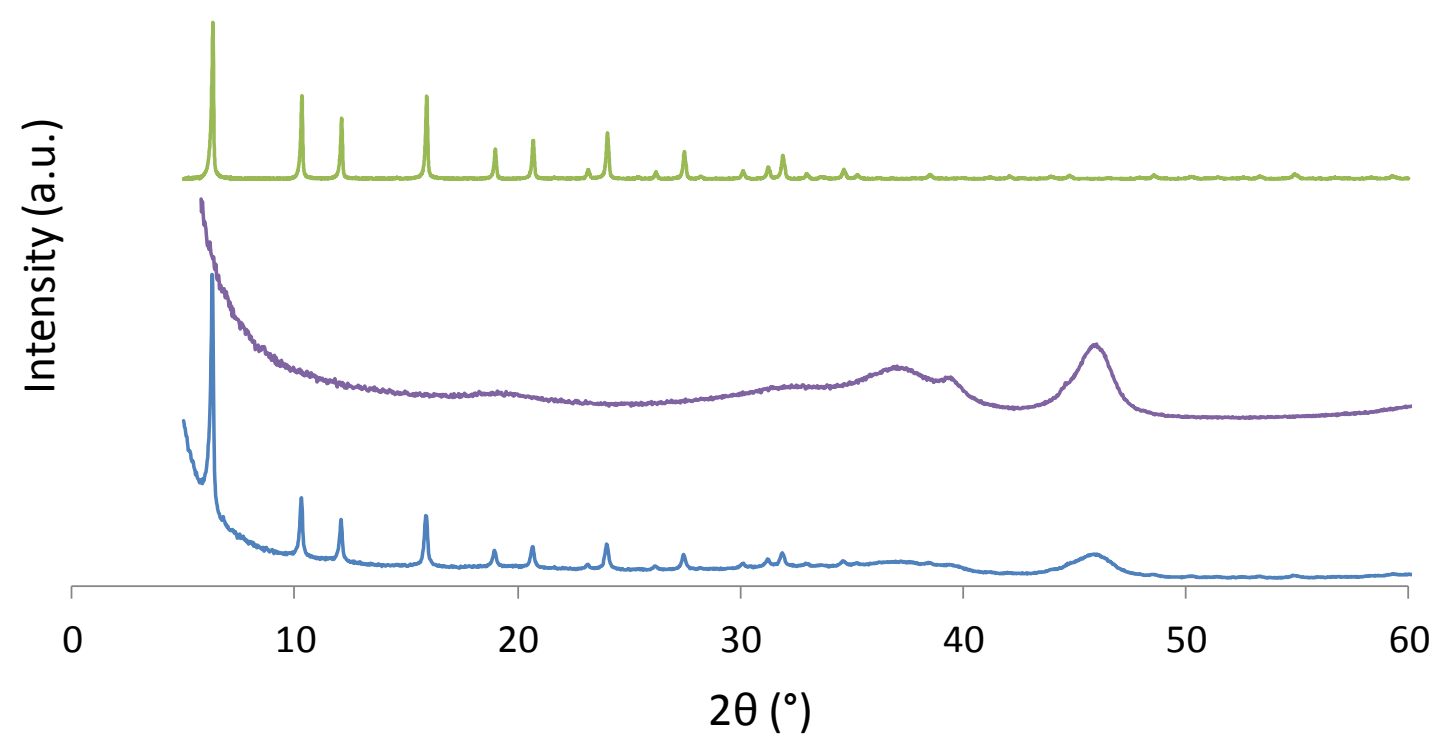

Figure 2: Diffraction patterns of $\mathrm{HUSY}+\mathrm{Al}_{2} \mathrm{O}_{3}, \mathrm{Al}_{2} \mathrm{O}_{3}$, and $\mathrm{HUSY}$ (from bottom to top).

The textural properties of all samples were compiled on Table 1. The HUSY sample is characterized by a large micropore volume due to its large pores as well as the presence of supercages. At the origin of the mesoporosity of HUSY sample are $10 \mathrm{~nm}$ pores obtained by dealumination of the original aluminium-rich zeolite [46]. Macropores were not detected in any of the samples excluding. Thus, for the shaped supports, the presence of defects generated during the shaping process (e.g. cracks and large cavities). Such defects could lead to a lack of mechanical strength and heterogeneous distribution of zeolite crystals throughout the extrudates. Further insight can be acquired by comparing the measured properties of shaped HUSY sample to those of HUSY zeolite and pure shaped $\mathrm{Al}_{2} \mathrm{O}_{3}$, weighed by the fraction of 
zeolite and $\mathrm{Al}_{2} \mathrm{O}_{3}$ in the support (Figure 3). After shaping, $83 \%$ of the micropore volume was preserved. Zeolite can be considered responsible for all the microporosity in extrudates as $\mathrm{Al}_{2} \mathrm{O}_{3}$ did not hold any pores with less than $5 \mathrm{~nm}$. Therefore, the similar microporous volume of shaped supports to that of parent zeolites hints at the preservation of zeolite structure after shaping in agreement with the XRD measurements. It furthermore reveals that the alumina platelets did not block the access to the zeolite micropores to a significant extend. The mesopore volume of $\mathrm{Al}_{2} \mathrm{O}_{3}+\mathrm{HUSY}$ sample also corresponded to the weighted sum of the $\mathrm{Al}_{2} \mathrm{O}_{3}$ and HUSY solids. It revealed that alumina crystallites stacking was not modified by the HUSY presence during the shaping process.

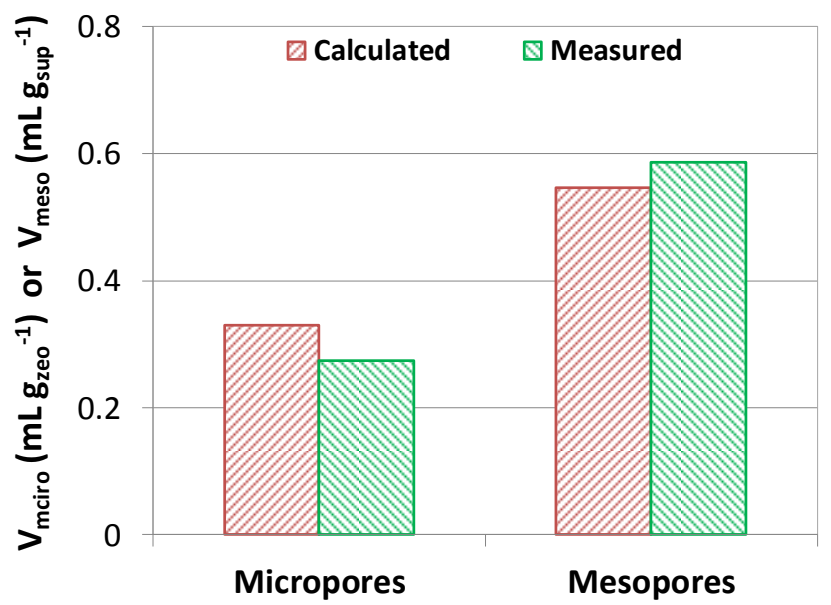

Figure 3: Calculated and measured volumes of micropores and mesopores for unshaped and shaped samples by $\mathrm{N}_{2}$ adsorption-desorption.

\section{Acidic properties}

Assessing the Brønsted acidity of shaped zeolitic support is not straightforward. Some authors have used $\mathrm{NH}_{3}$-TPD $[27,56]$ but, as this technique is not sensitive to the nature of the acid sites, the Lewis acidity of $\mathrm{y}-\mathrm{Al}_{2} \mathrm{O}_{3}$ can complicate the interpretation of the experimental results. Consecutive pyridine adsorption and thermodesorption followed by in situ FTIR has been also performed in shaped supports [34] and it is the most common method to characterize zeolite acidity. In this case, the pyridine-acid sites interaction leads to two differents IR bands [57] enabling a separate quantification of Brønsted and Lewis. In Figure S4, the spectra of HUSY zeolite is compared to those of shaped support and the corresponding mechanical mixture of HUSY zeolite with grinded $\mathrm{Y}-\mathrm{Al}_{2} \mathrm{O}_{3}$ support. In presence of alumina, the IR contribution corresponding to zeolite Brønsted acid sites was clearly reduced. This can be easily explained by a dilution effect: zeolite corresponded to only $16.5 \mathrm{wt} . \%$ of the shaped sample and the alumina does not have any Brønsted acidity, as probed by pyridine at $423 \mathrm{~K}$. Unfortunately, this resulted in band intensities too weak to enable an estimation of the BAS concentration of after mechanical mixing or shaping. This should mean that a specific procedure should be used in order to probe the acidity of zeolites when diluted with a binder, even if the same solids are at 
stake. To overcome such problem, the Brønsted acidity of shaped HUSY was compared to that of parent zeolite through a model reaction catalyzed by such acid sites.

The selected reaction was the isomerization of $m$-xylene [58,59]. All samples were tested in powder form, at a similar m-xylene/zeolite space velocity, and the activity was expressed per zeolite mass. The catalytic activity decreased with time-on-stream and this evolution was well described by a logarithmic equation (Figure S5). The activity at $1 \mathrm{~min}$ of reaction was extrapolated by these means and represented in Figure 4for the HUSY-based samples. The activity per zeolite mass was about $1.1 \mathrm{mmol} \mathrm{g}^{-1} \mathrm{~s}^{-1}$, for shaped and unshaped USY. This confirms that grinding and shaping procedures used herein have no impact on the intrinsic Brønsted activity of zeolite. Besides the shaping procedure in itself, the absence of cationic impurities in the boehmite employed is also believed to be of prime importance to preserve the Brønsted activity during shaping.

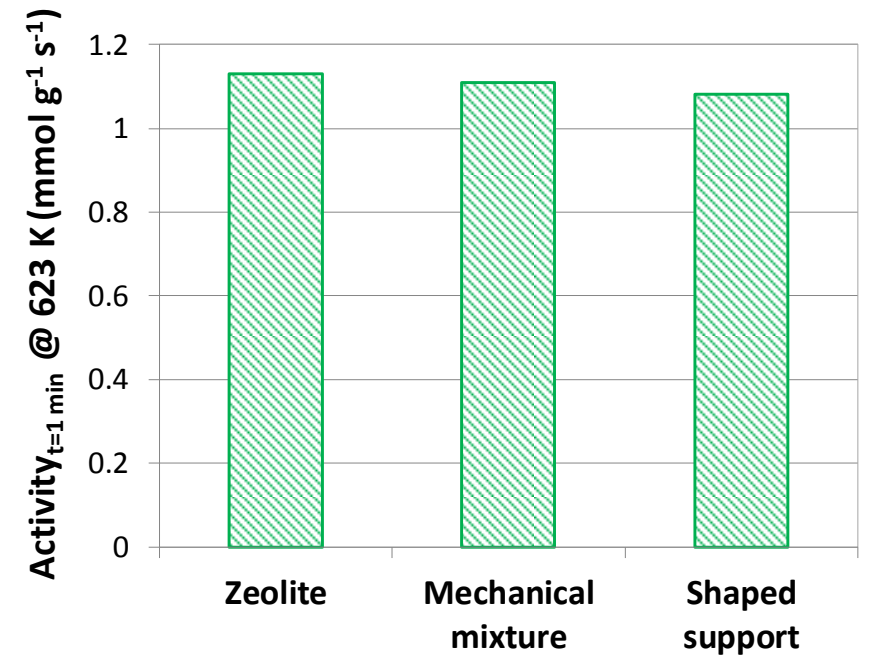

Figure 4: Activity per zeolite mass at $t=1$ min for HUSY, HUSY mechanically mixed with $\mathrm{Al}_{2} \mathrm{O}_{3}$, and shaped HUSY zeolite in $\mathrm{m}$-xylene isomerization.

\subsection{Characterization of the Pt-based bifunctional catalysts}

\section{Metal properties}

The metal properties of the samples are presented on Table 2. The Pt loading of bifunctional shaped catalysts was selected in order to cover a comparable range of $n_{P t} / n_{A l}$ to that of $\mathrm{Pt} / \mathrm{HUSY}$. The Pt content of all solids was determined by XRF. For the unshaped Pt/zeolite catalysts, the measured content was in agreement with the expected content within the experimental error $( \pm 10 \%)$. In contrast, for the the shaped support obtained by ionic exchange, the deviation increased along with the metal loading. The efficiency of ionic exchange has 
decreased with increasing metal loadings. Taking into account the concentration of zeolite framework $\mathrm{Al}^{\mathrm{IV}}$ sites in the shaped support (Table 1), the theoretical Pt ion exchange capacity of the HUSY-based extrudate is $2.6 \mathrm{wt} . \%$. The percentage of exchanged $\mathrm{Al}^{\mathrm{IV}}$ sites was thus only $10 \%$. However, about $30 \%$ of a HUSY are inaccessible to Pt precursors, due to the small pore aperture of sodalite cages [60]. Furthermore, the presence of a competitor ion $\left(\mathrm{NH}_{4}{ }^{+}\right)$decreases the equilibrium amount of exchanged Pt.

The accessible metal on the samples was determined by oxygen titration of chemisorbed hydrogen. The very low $\mathrm{Pt}$ content in the $0.07 \mathrm{Pt} /\left(\mathrm{HUSY}+\mathrm{Al}_{2} \mathrm{O}_{3}\right)$ precluded the evaluation of $\mathrm{Pt}$ dispersion by $\mathrm{O}_{2}-\mathrm{H}_{2}$ titration. For the other two samples, the Pt dispersions were comprised in a narrow range with a mean value of $73 \%$. The amount of accessible metal per gram of catalyst was then calculated and the average value of dispersion was used for the $0.07 \mathrm{Pt} /\left(\mathrm{HUSY}+\mathrm{Al}_{2} \mathrm{O}_{3}\right)$ sample. The impact of $\mathrm{Pt}$ introduction on zeolite acidity should remain limited, due to the relatively small loading of $\mathrm{Pt}(<1$ wt.\%) introduced by incipient wetness impregnation. Hence, the concentration of Brønsted acid sites in the catalysts was considered similar to that of parent HUSY zeolite. In this way, the metal to acid sites ratio $\left(n_{P_{t}} / n_{A I}\right)$ was estimated for each catalyst. In general, the shaped catalysts cover superior $n_{\mathrm{Pt}} / \mathrm{n}_{\mathrm{Al}}$. The low zeolite content in the shaped supports (ca. 17 wt.\%) as well as their superior Pt dispersions were at the origin of such difference.

Table 2: Pt loading and dispersion, accessible Pt and metal to acid sites ratio for bifunctional catalysts.

\begin{tabular}{|c|c|c|c|c|c|c|}
\hline Catalyst & $\begin{array}{c}\text { Nominal } \\
\text { Pt loading } \\
\text { (wt.\%) }\end{array}$ & $\begin{array}{c}\text { Measured } \\
\text { Pt loading } \\
\text { (wt.\%) }\end{array}$ & $\begin{array}{l}\text { Dispersion } \\
(\%)\end{array}$ & $\stackrel{\mathrm{n}_{\mathrm{Pt}}}{\left(\mu \mathrm{mol} \mathrm{g}^{-1}\right)}$ & $\mathrm{n}_{\mathrm{Pt}} / \mathrm{n}_{\mathrm{AI}}$ & $\begin{array}{c}\mathrm{Pt} \\
\text { distribution } \\
\text { coefficient }\end{array}$ \\
\hline $0.1 \mathrm{Pt} / \mathrm{HUSY}$ & 0.10 & 0.10 & 53 & 3 & 0.003 & - \\
\hline $0.4 \mathrm{Pt} / \mathrm{HUSY}$ & 0.40 & 0.42 & 53 & 11 & 0.013 & - \\
\hline 0.7Pt/HUSY & 0.70 & 0.73 & 52 & 19 & 0.023 & - \\
\hline $0.07 \mathrm{Pt} /\left(\mathrm{HUSY}+\mathrm{Al}_{2} \mathrm{O}_{3}\right)$ & 0.063 & 0.065 & $<M D L$ & $2^{a}$ & 0.018 & 0.72 \\
\hline $0.11 \mathrm{Pt} /\left(\mathrm{HUSY}+\mathrm{Al}_{2} \mathrm{O}_{3}\right)$ & 0.125 & 0.11 & 71 & 4 & 0.030 & 0.95 \\
\hline $0.25 \mathrm{Pt} /\left(\mathrm{HUSY}+\mathrm{Al}_{2} \mathrm{O}_{3}\right)$ & 0.375 & 0.25 & 76 & 10 & 0.071 & 0.99 \\
\hline
\end{tabular}

${ }^{a}$ Assuming a Pt dispersion of $73 \%$ (average of $\mathrm{Pt} /\left(\mathrm{HUSY}+\mathrm{Al}_{2} \mathrm{O}_{3}\right)$ solids).

\section{Metal location}

The average elemental profiles of $\mathrm{Pt}, \mathrm{Si}$ and $\mathrm{Al}$ along the diameter of extrudates are depicted in Figure 5 for $\mathrm{Pt} /\left(\right.$ zeolite $+\mathrm{Al}_{2} \mathrm{O}_{3}$ ) samples. Most of the profiles revealed an uniform distribution of $\mathrm{Pt}$ all along the diameter of the extrudate. The exception was the $\mathrm{Pt}$ profile for $0.07 \mathrm{Pt} /\left(\mathrm{HUSY}+\mathrm{Al}_{2} \mathrm{O}_{3}\right)$ sample in which a lower concentration of $\mathrm{Pt}$ was noticeable at the core of the extrudate. In order to condense the elemental profiles into a single parameter, a distribution coefficient can be used. The distribution coefficient is the ratio of the mean concentration along 
the extrudate to overall concentration [50] (vide Section 2.2). In the case of platinum (Figure 6a), according to the distribution coefficient, the metal was uniformly distributed along the extrudates of samples $0.11 \mathrm{Pt} /\left(\mathrm{HUSY}+\mathrm{Al}_{2} \mathrm{O}_{3}\right)$ and $0.25 \mathrm{Pt} /\left(\mathrm{HUSY}+\mathrm{Al}_{2} \mathrm{O}_{3}\right)$ but not for those of $0.07 \mathrm{Pt} /\left(\mathrm{HUSY}+\mathrm{Al}_{2} \mathrm{O}_{3}\right)$ sample. In this case, the coefficient was markedly below one $(0.72)$ confirming the egg-shell like distribution previously qualitatively reported. The distribution coefficient for silicon was close to 1 for all samples (Figure 6a) revealing hence a uniform distribution of the zeolite along the extrudates diameter. This result corroborates the previous observations by SEM which pointed out a homogenous distribution of zeolite in the alumina.
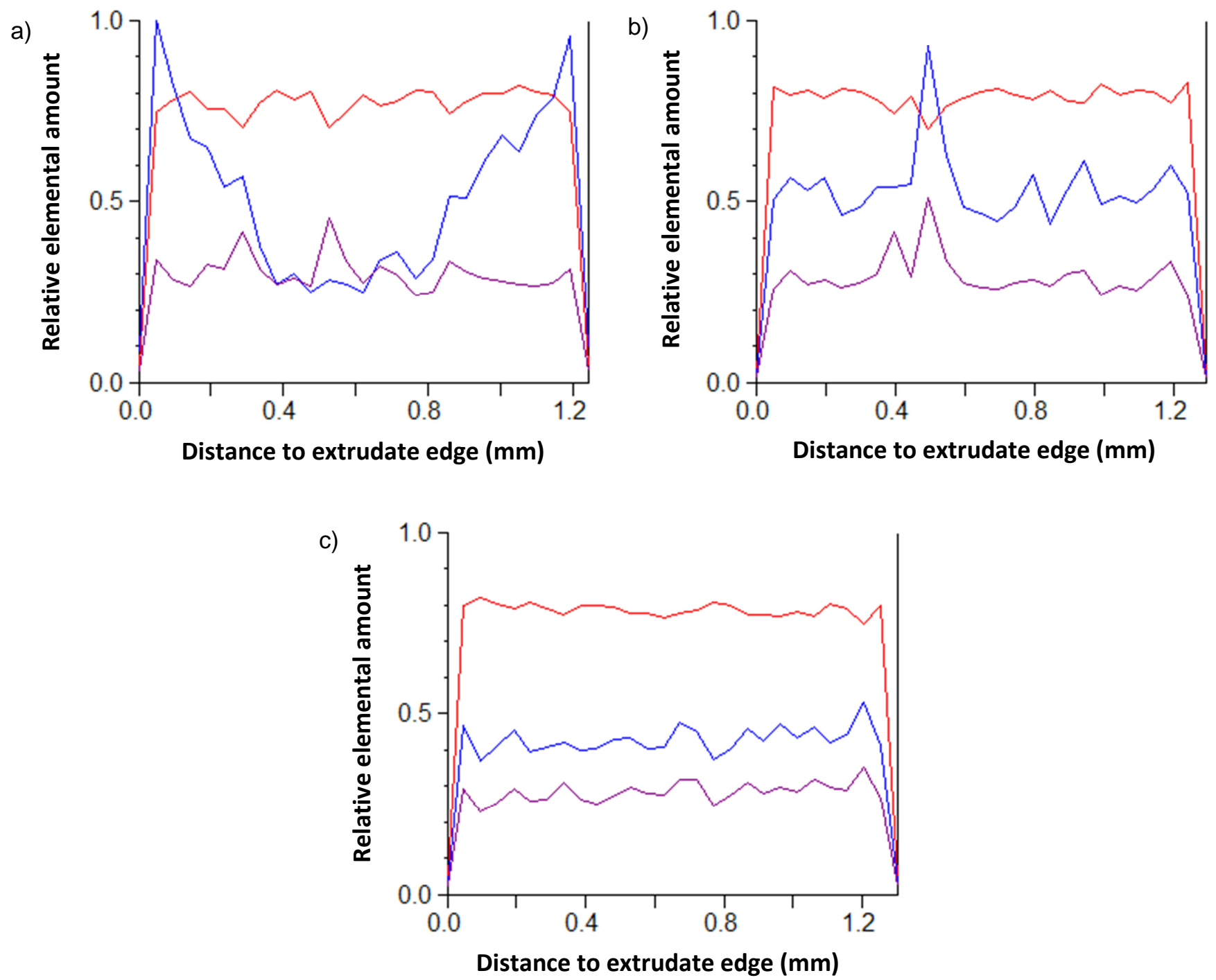

Figure 5: Average electron probe microanalysis profiles of $\mathrm{Al}$ (red), Si (purple), and Pt (blue) elements along the diameter of the extrudate for a) $0.07 \mathrm{Pt} /\left(\mathrm{HUSY}+\mathrm{Al}_{2} \mathrm{O}_{3}\right)$, b)

$0.11 \mathrm{Pt} /\left(\mathrm{HUSY}+\mathrm{Al}_{2} \mathrm{O}_{3}\right)$, and c) $0.25 \mathrm{Pt} /\left(\mathrm{HUSY}+\mathrm{Al}_{2} \mathrm{O}_{3}\right)$. Full ordinates scale is $100 \%$ for $\mathrm{Al}, 50 \%$ for $\mathrm{Si}$, and a) $0.1 \%$, b) $0.2 \%$, c) $0.5 \%$ for Pt.

As the concentration profiles of $\mathrm{Pt}$ and $\mathrm{Si}$ were simultaneously measured, the $\mathrm{Pt}$ concentration in presence of $\mathrm{Si}$ (i.e. presence of zeolite) and in absence of $\mathrm{Si}$ (i.e. presence of alumina only) 
can be differentiated. The Pt content in zeolite was thus estimated (vide Section 2.2 for calculations details) and compared to the Pt content deposed in the whole support (Figure 6b). For all three samples, the Pt content deposed in the HUSY zeolite nearly matched with the whole Pt deposed on the support. In other words, the Pt was preferentially introduced in the zeolite crystals with only a negligible amount of Pt located in the alumina in agreement with the selected procedure for metal introduction. In fact, the selective deposition of $\mathrm{Pt}$ in the zeolite has been reported to be due to the ionic exchange of the counter-ions of the zeolite Bronsted sites by the $\mathrm{Pt}\left(\mathrm{NH}_{3}\right)_{4}{ }^{2+}$ precursor ions, in a solution with a $\mathrm{pH}$ above the point of zero charge of the zeolite but below that of the alumina [60]. As compared to $\mathrm{Pt} / \mathrm{HUSY}$, in $\mathrm{Pt} /\left(\mathrm{HUSY}+\mathrm{Al}_{2} \mathrm{O}_{3}\right)$ the $\mathrm{Pt}$ was also located in the zeolite crystals. However, there is a second scale in terms of Pt location that arises: the macroscopic scale, induced by the extrudate diameter. The macroscopic distribution of Pt was different among the shaped samples, with the lowest Pt loading leading to a local concentration of $\mathrm{Pt}$ in the extrudate edges of $0.089 \%$ whereas that in the centre amounted to $0.026 \%$. The local concentration of $\mathrm{Pt}$ in the edges was hence more than three times greater than in the centre of the extrudate. As the solution starts penetrating in the extrudates, the Pt precursors can be exchanged into the zeolite. Whenever the ionic exchange occurs faster than the solution diffusion, the metal will be first deposed in the edges of the shaped material and then proceed to the core of the extrudate. For low concentrations of precursor in solution, this can lead to the consumption of most of the $\mathrm{Pt}$ in the first contact of the solution with shaped bodies creating then a gradient of concentration from the edges to the core of the extrudate. The egg-shell $\mathrm{Pt}$ distribution for $0.07 \mathrm{Pt} /\left(\mathrm{HUSY}+\mathrm{Al}_{2} \mathrm{O}_{3}\right)$ sample is therefore explained by low Pt concentration in solution and the rapid ionic exchange of the Pt precursor ions into the Brønsted acid sites of the zeolite despite the presence of the ammonium competitor.
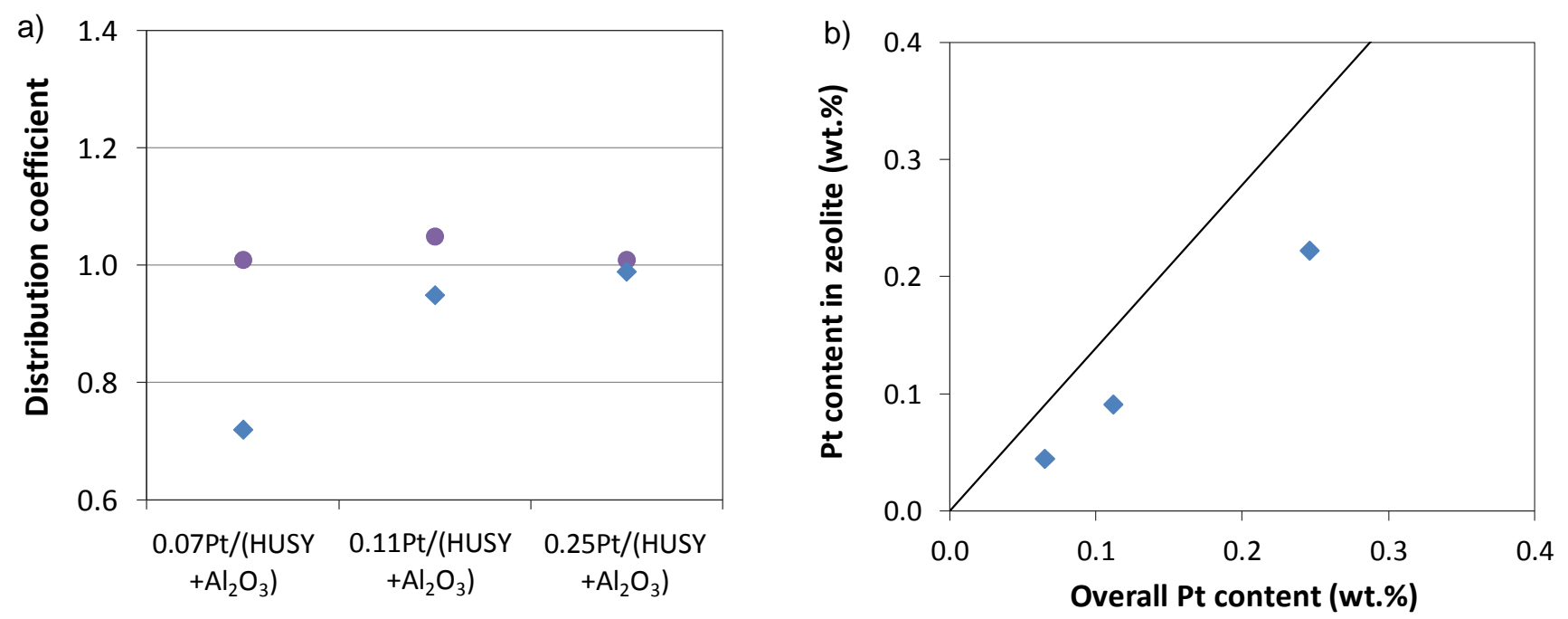

Figure 6: a) Distribution coefficient of $\operatorname{Pt}(\diamond)$ and $\mathrm{Si}(\bullet)$ measured by electron probe micro analysis as a function of the Pt content. b) Pt content deposed in the alumina vs. overall $\mathrm{Pt}$ content deposed in the support. $\mathrm{Pt} /\left(\mathrm{HUSY}+\mathrm{Al}_{2} \mathrm{O}_{3}\right)$ samples 


\subsection{Hydroisomerization of $n$-hexadecane}

As the catalytic results for Pt/HUSY series were discussed in detail in a previous work [18], the focus herein will be held at those of $\mathrm{Pt} /\left(\mathrm{HUSY}+\mathrm{Al}_{2} \mathrm{O}_{3}\right)$ series and the pertinent comparisons.

\section{Catalytic activity}

The consumption of $n$-paraffins in hydroconversion reactions has been shown to be first-order in the paraffin concentration $[18,61,62]$. The first-order plots for the hydroisomerization of $n$ hexadecane over $\mathrm{Pt} /\left(\mathrm{HUSY}+\mathrm{Al}_{2} \mathrm{O}_{3}\right)$ (Figure S5) reveal an excellent fit regardless of reaction temperature or catalyst confirming the abovementioned observations in literature. Using the apparent kinetic constant, the catalytic activity was determined for each catalyst at $483 \mathrm{~K}$ (Table 3). In Figure 7a), the catalyst series are compared. Regardless of Pt loading, as awaited, $\mathrm{Pt} / \mathrm{HUSY}$ catalysts revealed a superior activity than $\mathrm{Pt} /\left(\mathrm{HUSY}+\mathrm{Al}_{2} \mathrm{O}_{3}\right)$ ones. The difference in catalytic activity corresponds, at iso-conversion, to a gap in reaction temperature of about $30 \mathrm{~K}$. Some practical implications arise as the reaction temperature may affect the catalytic performance, particularly the product selectivity. In order to have a comparable working temperature range for both catalyst series, slower space velocities were employed when testing the shaped catalysts $\left(0.1-1.1\right.$ vs. $\left.0.6 \mathrm{mg}_{n \text {-hexadecane }} g_{\text {catalyst }}{ }^{-1} \mathrm{~s}^{-1}\right)$.
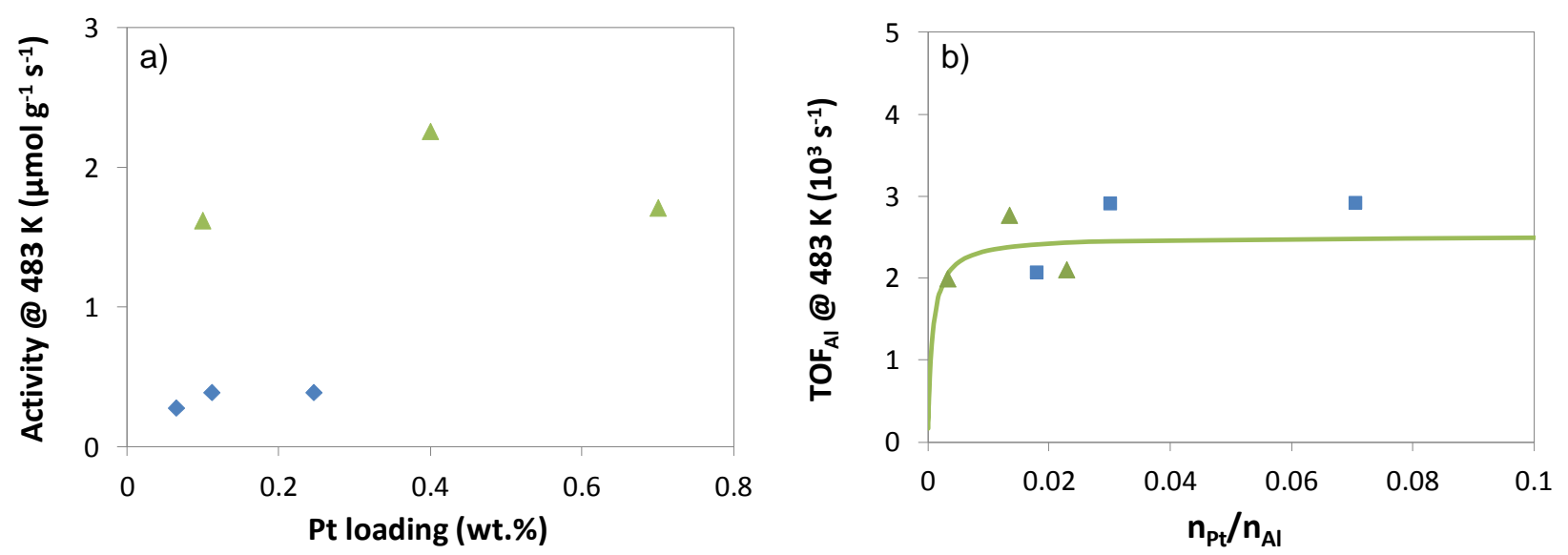

Figure 7: a) $n-\mathrm{C}_{16}$ hydroconversion activity as function of Pt loading and b) turnover frequency per protonic site as a function of $\mathrm{n}_{\mathrm{Pt}} / \mathrm{n}_{\mathrm{Al}}$ ratio. $\mathrm{Pt} / \mathrm{HUSY}(\Delta)[18]$ and $\mathrm{Pt} /\left(\mathrm{HUSY}+\mathrm{Al}_{2} \mathrm{O}_{3}\right)(\diamond)$ catalyst series. Symbols stand for experimental data and lines for model fitting results.

Table 3: Catalytic activity, turnover frequency over protonic sites at $483 \mathrm{~K}$ and maximum isomer yield.

\begin{tabular}{|c|c|c|c|}
\hline Sample & $\begin{array}{c}\text { Activity @ } 483 \mathrm{~K} \\
\left(\mu \mathrm{mol} \mathrm{g} \mathrm{g}^{-1} \mathrm{~s}^{-1}\right)\end{array}$ & $\begin{array}{c}\text { TOF }_{\mathrm{Al}} @ 483 \mathrm{~K} \\
\left(10^{3} \mathrm{~s}^{-1}\right)\end{array}$ & $\begin{array}{c}\text { Maximal } C_{16} \\
\text { isomers yield (\%) }\end{array}$ \\
\hline $0.1 \mathrm{Pt} / \mathrm{HUSY}$ & 1.62 & 2.0 & 46.5 \\
\hline $0.4 \mathrm{Pt} / \mathrm{HUSY}$ & 2.26 & 2.8 & 59.3 \\
\hline 0.7Pt/HUSY & 1.71 & 2.1 & 62.1 \\
\hline $0.07 \mathrm{Pt} /\left(\mathrm{HUSY}+\mathrm{Al}_{2} \mathrm{O}_{3}\right)$ & 0.28 & 2.1 & 47.4 \\
\hline
\end{tabular}




\begin{tabular}{llll}
\hline $\mathbf{0 . 1 1 P t} /\left(\mathrm{HUSY}+\mathrm{Al}_{2} \mathrm{O}_{3}\right)$ & 0.39 & 2.9 & 58.6 \\
$\mathbf{0 . 2 5 P t} /\left(\mathrm{HUSY}+\mathrm{Al}_{2} \mathrm{O}_{3}\right)$ & 0.39 & 2.9 & 60.6 \\
\hline
\end{tabular}

\section{Evolution of turnover frequency with $n_{\mathrm{Pt}} / \mathrm{n}_{\mathrm{Al}}$}

In order to fully understand the causes of the lower activity of shaped catalysts, the turnover frequency over the protonic sites of both catalyst series should be compared. As the turnover frequency depends also on the metal to acid sites ratio $[18,23]$, the average turnover $\left(\right.$ TOF $\left._{A \mathrm{I}}\right)$ was plotted as function of $n_{P_{t}} / n_{A l}$ ratio in Figure $7 b$ ). This evolution has been modelled previously for Pt/HUSY [18] and so the model results for Pt/HUSY were also included in the comparison. The $\mathrm{TOF}_{\mathrm{Al}}$ obtained over $\mathrm{Pt} /\left(\mathrm{HUSY}+\mathrm{Al}_{2} \mathrm{O}_{3}\right)$ catalysts was strikingly comparable to those of $\mathrm{Pt} / \mathrm{HUSY}$ catalysts. The underlying implication is that the available Brønsted sites hold a similar intrinsic activity regardless of the differences in catalyst formulation. Furthermore, as the TOF $_{\mathrm{Al}}$ was independent of $n_{\mathrm{Pt}} / \mathrm{n}_{\mathrm{Al}}$, according to the classical bifunctionnal mechanism, this implies that the dehydrogenation rate over the $\mathrm{HDH}$ function should have been sufficient to feed all the Brønsted sites in the $\mathrm{HUSY}+\mathrm{Al}_{2} \mathrm{O}_{3}$ support with intermediate olefinic species [23].

\section{Product selectivity and yield}

The lumped product distribution as function of conversion for different reaction temperatures is depicted in Figure 8 for $0.25 \mathrm{Pt} /\left(\mathrm{HUSY}+\mathrm{Al}_{2} \mathrm{O}_{3}\right)$ catalyst. Considering the evolution of product selectivity at low conversion, monobranched (MB) and multibranched (MTB) isomers appear as primary products. MB products were predominant up to $50 \%$ of conversion and MTB products for conversions between $50 \%$ and $90 \%$. Cracking products (CP) selectivity stays below $5 \%$ for conversions lower than $40 \%$ and increase steadily with conversion. All in all, this is an indication of a rather consecutive apparent reaction scheme: $n-C_{16} \rightarrow$ MB $\rightarrow$ MTB $\rightarrow$ CP [23]. Additionally, the evolution of the products selectivities with conversion were the same, irrespectively of the reaction temperature. In other words, a $25 \mathrm{~K}$ shift in the reaction temperature did not modify the catalyst selectivity in the lumped products. It has been reported in literature that, for wellbalanced catalysts, the same product selectivity can be obtained over relatively wide ranges of operating conditions $[63,64]$ (giving rise to the so-called unique curve of feed isomer yield). From the practical point of view, this means that the catalysts can be compared in terms of product yield even if discrepancies in the reaction temperature are present, as in this case. 


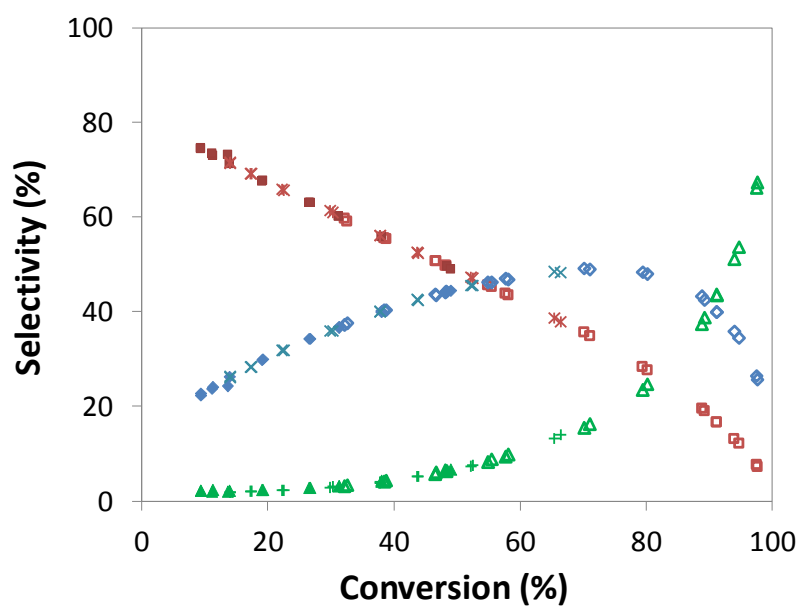

Figure 8: Monobranched $(\square)$ and multibranched $(\diamond) C_{16}$ isomers, and cracking $(\Delta)$ products selectivity as function of conversion at $483 \mathrm{~K}$ (closed symbols), $488 \mathrm{~K}$ (cross symbols), and 498 $\mathrm{K}$ (open symbols), for $0.25 \mathrm{Pt} /\left(\mathrm{HUSY}+\mathrm{Al}_{2} \mathrm{O}_{3}\right)$.

The $\mathrm{C}_{16}$ isomer yield, i.e. the sum of MB and MTB yields, was represented as function of the conversion for $\mathrm{Pt} /\left(\mathrm{HUSY}+\mathrm{Al}_{2} \mathrm{O}_{3}\right)$ catalysts (Figure 9a). For catalysts loaded with 0.11 and $0.25 \%$ $\mathrm{Pt}$, the evolution of $\mathrm{C}_{16}$ isomer yield with conversion were similar whereas that of $0.07 \mathrm{Pt} /\left(\mathrm{HUSY}+\mathrm{Al}_{2} \mathrm{O}_{3}\right)$ was clearly below the other two. The maximal $\mathrm{C}_{16}$ isomer yield was thus lower for $0.07 \mathrm{Pt} /\left(\mathrm{HUSY}+\mathrm{Al}_{2} \mathrm{O}_{3}\right)$ as well as the conversion level at which it occurred. Both observations point to a more parallel reaction scheme over the $0.07 \mathrm{Pt} /\left(\mathrm{HUSY}+\mathrm{Al}_{2} \mathrm{O}_{3}\right)$ catalyst which can be associated with a longer residence time of intermediate olefins promoting consecutive acid-catalysed reactions and so cracking products, according to the classical bifunctional mechanism $[4,18,23]$. The high number of experimental points (due to a simultaneous change of reaction temperature and catalyst contact time) enabled the direct determination of the maximum of $\mathrm{C}_{16}$ isomer yield (Table 3). On the contrary, those of Pt/HUSY catalysts were previously determined with the help of a macrokinetic model [18].

Figure 9b) compares the catalysts with the highest Pt loading of each series (i.e. unshaped and shaped HUSY). The evolution of $\mathrm{C}_{16}$ isomer yield with conversion over $0.25 \mathrm{Pt} /\left(\mathrm{HUSY}+\mathrm{Al}_{2} \mathrm{O}_{3}\right)$ catalyst matched remarkably the one obtained with $0.7 \mathrm{Pt} / \mathrm{HUSY}$ catalyst. The two catalysts series revealed hence the same selectivity towards isomerisation for sufficiently high $\mathrm{Pt}$ loadings. In such case, the intrinsic performance of $\mathrm{Pt} / \mathrm{HUSY}$ and $\mathrm{Pt} /\left(\mathrm{HUSY}+\mathrm{Al}_{2} \mathrm{O}_{3}\right)$ catalysts was noticeably alike. To get hold at the full picture, the metal to acid sites ratio should be also taken into account. For a given zeolite, a unique relation between the maximal $\mathrm{C}_{16}$ isomer yield $\left(Y_{i-C 16, \max }\right)$ and $n_{P t} / n_{A l}$ can be established for Pt/zeolite catalysts [18]. This relationship will be then analysed for the $\mathrm{Pt} /\left(\right.$ zeolite $\left.+\mathrm{Al}_{2} \mathrm{O}_{3}\right)$ catalysts. 

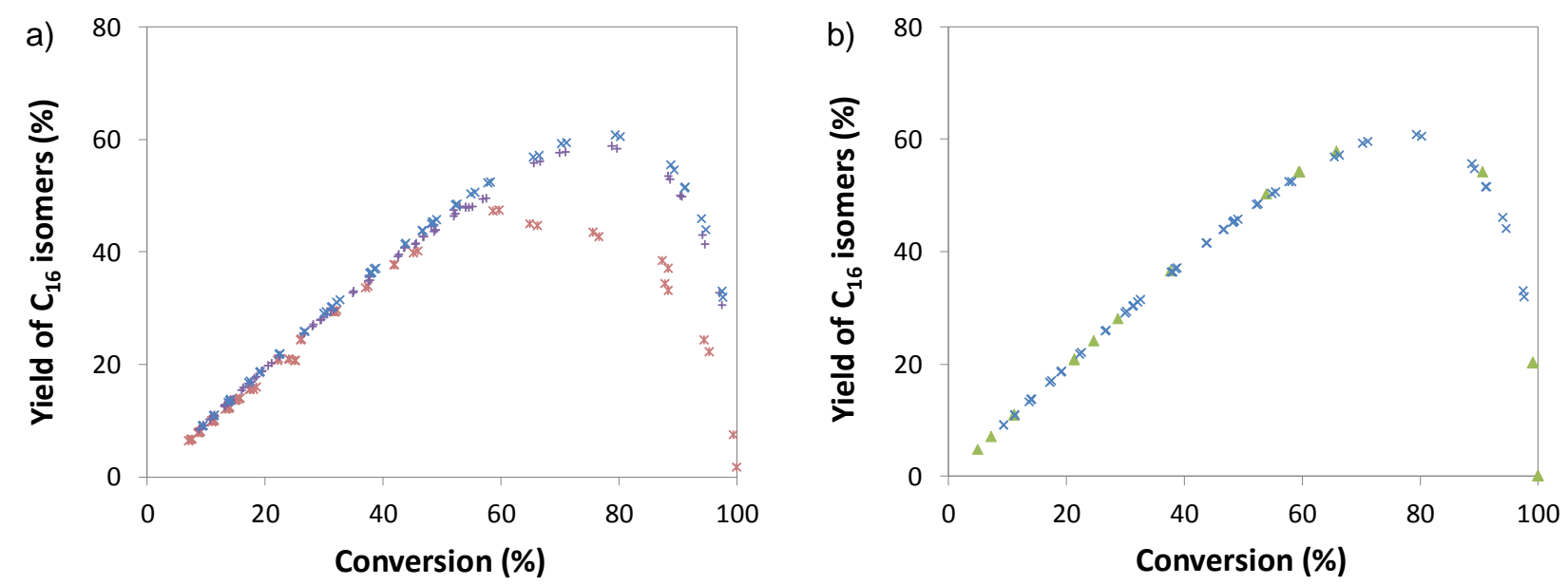

Figure 9: Yield of feed isomers as function of conversion. a) $\mathrm{Pt} /\left(\mathrm{HUSY}+\mathrm{Al}_{2} \mathrm{O}_{3}\right)$ series with different Pt loadings: $0.07 \%(*), 0.11 \%(+)$, and $0.25 \%(\times)$. b) $0.7 \mathrm{Pt} / \mathrm{HUSY}(\Delta)$ and $0.25 \mathrm{Pt} /\left(\mathrm{HUSY}+\mathrm{Al}_{2} \mathrm{O}_{3}\right)(\times)$ catalysts.

\section{Evolution of maximal $\mathrm{C}_{16}$ isomer yield with $\mathrm{n}_{\mathrm{Pt}} / \mathrm{n}_{\mathrm{Al}}$}

The comparison of catalysts series is presented in Figure 10 through the evolution of maximal $\mathrm{C}_{16}$ isomer yield $\left(\mathrm{Y}_{\mathrm{i}-\mathrm{C} 16, \max }\right)$ with $\mathrm{n}_{\mathrm{Pt}} / \mathrm{n}_{\mathrm{Al}}$. For high $\mathrm{n}_{\mathrm{Pt}} / \mathrm{n}_{\mathrm{Al}}$ values $(0.03), \mathrm{Pt} /\left(\mathrm{HUSY}+\mathrm{Al}_{2} \mathrm{O}_{3}\right)$ catalyst revealed a fairly constant $\mathrm{Y}_{\mathrm{i}-\mathrm{C16} \text {,max }}$ corresponding nearly to the plateau of $\mathrm{Pt} / \mathrm{HUSY}$ series. Therefore, in such case, the acid function of the shaped catalysts was "well-balanced" by its $\mathrm{HDH}$ function. In other words, the hydrogenation/dehydrogenation reactions were much faster than the acid-catalysed ones becoming those the rate-limiting steps [65]. For well-balanced catalysts, the apparent reaction scheme is thus governed by the zeolite properties and thereby intrinsic to the zeolite. Above all, this result confirms the similarity in the intrinsic selectivity of $\mathrm{Pt} / \mathrm{HUSY}$ and $\mathrm{Pt} /\left(\mathrm{HUSY}+\mathrm{Al}_{2} \mathrm{O}_{3}\right)$ catalysts to $\mathrm{C}_{16}$ isomers firstly revealed in the previous section.

Strikingly, for low $n_{\mathrm{Pt}} / \mathrm{n}_{\mathrm{Al}}$, specifically for the $0.07 \mathrm{Pt} /\left(\mathrm{HUSY}+\mathrm{Al}_{2} \mathrm{O}_{3}\right)$ catalyst, the shaped catalysts were not as selective as Pt/HUSY ones for similar $n_{P t} / n_{A l}$ ratio (around 0.02 ). This significant reduction in the $Y_{i-C 16, \max }$ cannot therefore be explained by a lack of the amount of hydrogenating sites for the catalyst as whole. At this point, the heterogeneity of Pt distribution in the extrudates should be taken into consideration because the catalytic behaviour depends not only on the zeolite intrinsic properties and on the overall metal to acid sites ratio but also on the distance between metal and acid sites [25,26]. 


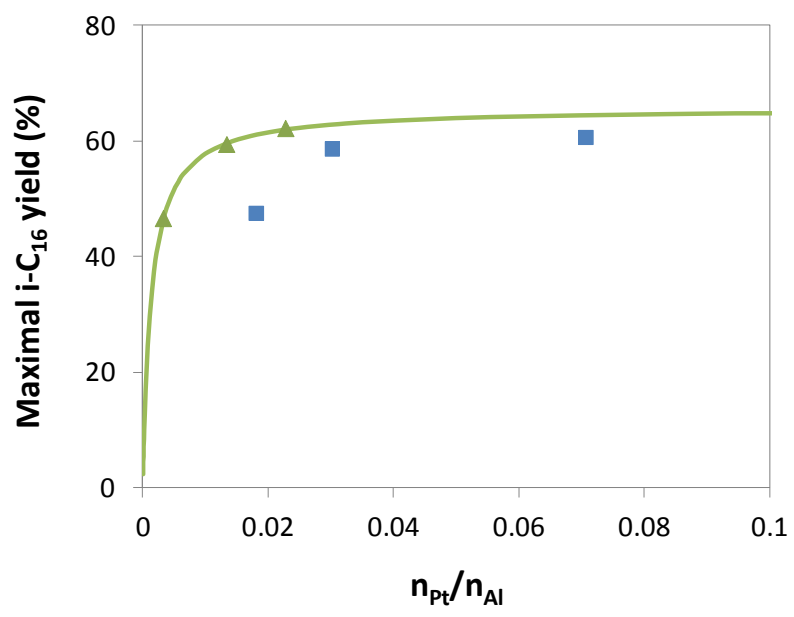

Figure 10: Maximal $C_{16}$ isomer yield as a function of the overall $n_{P t} / n_{A l}$ ratio. Pt/HUSY ( $\triangle$ ) [18] and $\mathrm{Pt} /\left(\mathrm{HUSY}+\mathrm{Al}_{2} \mathrm{O}_{3}\right)(\diamond)$ catalyst series. Symbols stand for experimental data and lines for model fitting results.

\section{The role of Pt macroscopic distribution}

The estimation of an average distance between $\mathrm{Pt}$ and Brønsted acid sites is virtually impossible due to the complexity of the system. As a result, we will focus on the calculation of a maximal Pt-acid sites distance taking into account well-known properties of the samples at question.

As abovementioned, an homogeneous distribution of Pt inside the zeolite crystal has been revealed for Pt/HUSY samples [46]. For such case, the maximal distance between Pt and acid sites ( $\mathrm{d}_{\mathrm{Pt} \text {-acid }}$ ) would correspond to half of the distance between two consecutive Pt particles $\left(\mathrm{d}_{\mathrm{Pt}}\right.$ $\left.\mathrm{Pt}_{\mathrm{t}}\right)$. Considering that $\mathrm{Pt}$ particles are homogenously dispersed throughout the support, we assume that each particle covers a cubic volume of support $\left(\mathrm{V}_{\mathrm{Pt} \text {-sup }}\right)$. The distance between $\mathrm{Pt}$ particles can be hence calculated from that support volume that surrounds a given particle from its neighbours. The volume of zeolite per zeolite gram corresponds to the bulk density ( $\rho_{\text {bulk }}=0.6$ $\mathrm{g} \mathrm{cm}^{-3}$ for HUSY zeolite). The number of Pt particles per gram of zeolite ( $\left.n_{\text {particles }}\right)$ can be estimated by the volume of Pt per gram of zeolite divided by the volume of each particle. Considering cubic particles and the particle diameter obtained by $\mathrm{H}_{2}-\mathrm{O}_{2}$ titration $\left(\mathrm{d}_{\mathrm{pt}}\right)$, the density of Pt $\left(21.45 \mathrm{~g} \mathrm{~cm}^{-3}\right)$ and the Pt loading $\left(\mathrm{x}_{\mathrm{Pt}}\right), \mathrm{d}_{\mathrm{Pt} \text {-acid }}$ can be ultimately calculated. In the case of shaped catalysts, as the platinum particles were also located inside the zeolite, the circumstances are therefore similar to those of $\mathrm{Pt} / \mathrm{HUSY}$ with $\mathrm{x}_{\mathrm{Pt}}$ corresponding to the mass of Pt per mass of zeolite. 


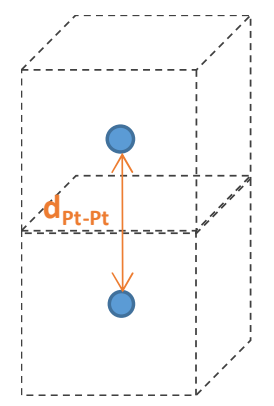

$$
\begin{gathered}
d_{P t-\text { acid }}=\frac{1}{2} d_{P t-P t}=\frac{1}{2} \sqrt[3]{V_{P t-s u p}}=\frac{1}{2} \sqrt[3]{\frac{\rho_{\text {bulk }}}{n_{\text {particles }}}}= \\
=\frac{1}{2} \sqrt[3]{\frac{\rho_{\text {bulk }}}{x_{P t} \rho_{P t} / d_{P t}^{3}}}
\end{gathered}
$$

The results for the Pt-acid sites distance calculations are presented in Table 4. It ranged from 30 to $10 \mathrm{~nm}$ from 0.1Pt/HUSY to 0.7Pt/HUSY sample. For the shaped Pt-catalysts, the distance was even shorter due to higher Pt concentration in the zeolite crystals ( $\left.\mathrm{X}_{\mathrm{Pt}}\right)$. It is also however mentioning that a 15-fold increase in $\mathrm{x}_{\mathrm{Pt}}$ led only to a 3-fold reduction in the maximal Pt-acid site distance. This can be explained by the cubic root factor on Pt loading (Equation 1) ruling out hence the use of Pt loading to tune the metal-acid sites distance in a bifunctional catalyst. In all cases, the maximal Pt-acid sites was in a narrow range 10-30 nm. According to literature reports, a distance shorter than a few micrometers is required to ensure that diffusion of olefinic intermediates is not rate-limiting $[25,26]$ pointing to an adequate intimacy between catalytic functions at the scale of zeolite crystals.

Meanwhile, when the shaped catalysts were crushed and sieved before the catalytic test, powder particles with a granulometry of 0.2-0.5 mm were formed. For $0.11 \mathrm{Pt} /\left(\mathrm{HUSY}+\mathrm{Al}_{2} \mathrm{O}_{3}\right)$ and $0.25 \mathrm{Pt} /\left(\mathrm{HUSY}+\mathrm{Al}_{2} \mathrm{O}_{3}\right)$ samples, as the metal was homogeneous distributed throughout the whole support, all the particles should have a comparable metal to acid sites ratio, similar to the overall ratio. Conversely, when $0.07 \mathrm{Pt} /\left(\mathrm{HUSY}+\mathrm{Al}_{2} \mathrm{O}_{3}\right)$ was crushed, the heterogeneous distribution of $\mathrm{Pt}$ throughout the extrudate should have resulted in different metal to acid sites ratios over the powder particles. As the particle size is about 100 times longer than required for the absence of diffusion limitations between the catalytic functions, this means that the olefins formed on one catalyst particle will not diffuse to another particle without reacting. In other words, the Pt of one particle will not balance the Brønsted acid sites located in another particle. Therefore, in such case, the overall metal to acid sites ratio of the catalyst is not representative of the local metal to acid sites ratios. The local $\mathrm{n}_{\mathrm{Pt}} / \mathrm{n}_{\mathrm{Al}}$ ratios should be therefore considered when evaluating the catalytic behaviour of the catalyst.

Table 4: Metal to acid sites ratio for the whole sample (overall) and in the centre of the

\begin{tabular}{|c|c|c|c|c|c|}
\hline Catalyst & $\left(\mathrm{n}_{\mathrm{Pt}} / \mathrm{n}_{\mathrm{Al}}\right)_{\text {overall }}$ & $\begin{array}{c}X_{p t} \\
\left(10^{2} g_{p t}\right. \\
\left.g_{\text {zeolite }}{ }^{-1}\right)\end{array}$ & $\begin{array}{c}\text { Maximal Pt- } \\
\text { acid site } \\
\text { distance } \\
(\mathrm{nm})\end{array}$ & $\begin{array}{c}\mathrm{Pt} \\
\text { distribution } \\
\text { coefficient }\end{array}$ & $\left(\mathrm{n}_{\mathrm{Pt}} / \mathrm{n}_{\mathrm{Al}}\right)_{\text {core }}$ \\
\hline 0.1Pt/HUSY & 0.003 & 0.10 & 30 & - & - \\
\hline 0.4Pt/HUSY & 0.013 & 0.42 & 19 & - & - \\
\hline 0.7Pt/HUSY & 0.023 & 0.73 & 16 & - & - \\
\hline $0.07 \mathrm{Pt} /\left(\mathrm{HUSY}+\mathrm{Al}_{2} \mathrm{O}_{3}\right)$ & 0.018 & 0.39 & 19 & 0.72 & 0.007 \\
\hline
\end{tabular}
extrudate (core) for bifunctional shaped catalysts. 


\begin{tabular}{|c|c|c|c|c|c|}
\hline $0.11 \mathrm{Pt} /\left(\mathrm{HUSY}+\mathrm{Al}_{2} \mathrm{O}_{3}\right)$ & 0.030 & 0.68 & 12 & 0.95 & 0.030 \\
\hline $0.25 \mathrm{Pt} /\left(\mathrm{HUSY}+\mathrm{Al}_{2} \mathrm{O}_{3}\right)$ & 0.071 & 1.49 & 9 & 0.99 & 0.071 \\
\hline
\end{tabular}

The local $n_{P t} / n_{A l}$ in the core of the extrudates was then calculated for each catalyst through the Pt content measured by EPMA in a radius of $50 \mu \mathrm{m}$ from the centre of the extrudate and assuming the same metal dispersion throughout the whole extrudate (Table 4). In the case of $0.07 \mathrm{Pt} /\left(\mathrm{HUSY}+\mathrm{Al}_{2} \mathrm{O}_{3}\right)$, the metal to acid sites ratio at the core of the extrudate was less than half the overall ratio. Comparing to the edge of the extrudate, the $\mathrm{n}_{\mathrm{Pt}} / \mathrm{n}_{\mathrm{Al}}$ in the core was 3.4 times lower. The heterogeneous macroscopic distribution of Pt resulted, hence, in catalyst particles with clearly different metal to acid sites ratios after crushing and sieving. In order to investigate the catalytic implications of such differences, one can consider a model case. In this hypothetical catalyst, only two populations of particles with different metal to acid sites ratio exist: one holding $n_{P t} / n_{A l}=0.001$ and another holding $\left(n_{P t} / n_{A I}\right)=0.015$. The maximal $C_{16}$ isomer yield of the catalyst would correspond to weighed average of the $Y_{i-C 16, \text { max }}$ at the core and at the edge of the extrudate. In other words, the $Y_{i-C 16, \max }$ of the catalyst would lie on a straight line unifying the two particle populations with the coordinates $\left(n_{P_{t}} / n_{A l} ; Y_{i-C 16, m a x}\right)$. Regardless of weight giving to each population, the catalyst performance would be always lower than that of catalyst with the same overall $n_{P t} / n_{A l}$ lying in the simulated $Y_{i-C 16, m a x}$ curve. The result is a positive effect on the isomerization yield when $\mathrm{Pt}$ is homogeneously distributed. The inferior performance of the $0.07 \mathrm{Pt} /\left(\mathrm{HUSY}+\mathrm{Al}_{2} \mathrm{O}_{3}\right)$ catalyst can be thus tentatively explained by the heterogeneous macroscopic distribution of $\mathrm{Pt}$ resulting in a poorer balance between the metal and acid sites as compared to that of a homogeneous Pt distribution for the same overall $\mathrm{n}_{\mathrm{Pt}} / \mathrm{n}_{\mathrm{Al}}$ ratio.

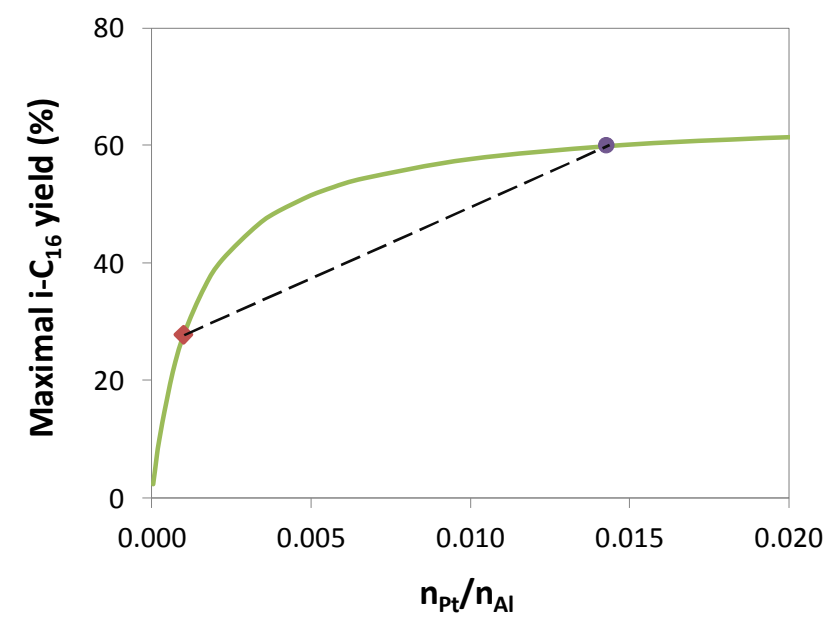

Figure 11: Simulation results for the maximal $\mathrm{C}_{16}$ isomer yield as a function of $\mathrm{n}_{\mathrm{Pt}} / \mathrm{n}_{\mathrm{Al}}$ ratio for mixtures $\mathrm{Pt} /\left(\mathrm{HUSY}+\mathrm{Al}_{2} \mathrm{O}_{3}\right)$. 


\section{Discussion}

As mentioned in the introduction, the shaping of zeolites is barely studied in the open literature. It is frequently described as a complex process during which the zeolite can be significantly modified. In this work, zeolites were extruded with boehmite free of cationic impurities and fully characterized after the adequate thermal treatments. The same features in terms of zeolite structure, texture and Brønsted acidity were observed before and after shaping hinting to a full preservation of the zeolite properties in the extrudates. Our results differ from most of the literature reports that describe zeolite-binder interactions resulting, frequently, in the neutralization of the Brønsted acid sites [32-35]. However, those are beneficial effects to the reactions under study. In the case of hydroconversion, the main goal of zeolite shaping is to retain the intrinsic properties of the acidic function as designed for an optimal performance (i.e. as in the powder form) and no reports exist up to now, to our knowledge. The procedure herein executed met, hence, that criterion proving that shaping of zeolites can be carried out with full preservation of its properties.

The repercussions of the scale-up from powder to shaped bodies are not restrained however to the properties of the zeolite, when bifonctionnal catalysts are at stake. Modifications on the properties of the metal phase, that was previously deposed directly in the zeolite and it is now introduced in the extrudates, are also expected. For Pt/zeolite samples, platinum was introduced directly in the zeolite by incipient wetness impregnation whilst, Pt introduction in the extrudates was carried out by ionic exchange with competition. In the latter, improved metal dispersions were obtained (50\% vs. $73 \%$ ) and, as the zeolite is diluted by the binder when shaped, remarkably greater metal to acid sites ratios can be obtained over shaped catalysts as compared to powder zeolites. On the other hand, a lower catalytic activity per gram of catalyst is to be always expected due to the lower zeolite content in shaped catalysts.

In the shaped samples, two special scales have to be considered: the nanoscale and the macroscale. At the nanoscale, the Pt was preferentially located in the zeolite, like in Pt/zeolite samples. At the macroscale, however, Pt was not always uniformly distributed along the extrudates diameter. For the lowest Pt loading in the shaped extrudates, it was preferentially deposed in external surface of the trilobe extrudates. When crushed to powder catalyst, the catalyst behaves as a mechanical mixture of catalysts holding different metal to acid sites ratio. The consequence is, at the same overall $n_{\mathrm{Pt}} / \mathrm{n}_{\mathrm{Al}}$, a lower $\mathrm{C}_{16}$ isomers yield for catalysts with poor macroscopic Pt distribution. It is also worth mentioning that the reduction of the granulometry of the shaped catalysts before the catalytic test ensured both the fulfilment of the criteria for a plug-flow reactor operation and the direct comparison of catalytic behaviour to unshaped catalysts. Concomitantly, the critical macroscopic dimensions, i.e. half of the smallest particle dimension, remained in the same order of magnitude: $0.1-0.3 \mathrm{~mm}$ for crushed and $0.6 \mathrm{~mm}$ for 
non-crushed shaped catalysts enabling the observation of catalytic phenomena similar to those occurring when the shaped catalyst are not crushed.

Our results agree with the first study on the importance of the macroscopic Pt distribution [66] offering now an insight into the metal-acid sites distance in such case as well as evidence for the poor balance between metal and acid functions. This also agrees generically with the criterion deduced by Weisz for the minimal distance between metal and acid sites [25] which can be converted as the number of acid steps undergone by olefinic intermediates during their diffusion between two Pt sites [26]. Most of the studies have shown hence that the maximal intimacy between metal and acid sites enhances the selectivity in feed isomers. In contrast, it has been suggested recently that improved selectivity in feed isomers when $\mathrm{Pt}$ is deposed in the alumina binder instead of the zeolite [27]. Herein a poor distribution of Pt throughout the extrudates has been demonstrated to have a significant detrimental effect in the catalyst selectivity. Further studies are still required but most of the evidence so far seems to uphold the importance of intimacy between metal and acid sites in the development of bifunctional catalysts for the hydroisomerization of long chain $n$-paraffins. Finally, $n$-hexadecane hydroconversion test can be conveniently used to check the homogeneous distribution of the metallic function within a shaped catalyst. Similar conclusions were drawn in the past for the $n$ hexane hydroconversion test [66].

\section{Conclusion}

This work aimed at shedding light on the parameters to be controlled during the scale-up of bifunctional catalysts from powder to shaped bodies. The focus was held both at the impact of shaping on the zeolite properties and at the metal properties of Pt-containing samples.

The employed shaping procedure enabled the full preservation of zeolite framework and its properties. The structural features of zeolites in the shaped supports were analogous to those of parent zeolites and the microporous volume was mostly retained after shaping. Likewise, the activity of Brønsted acid sites was similar before and after shaping. Modifications on the metal phase location, that was previously deposed on the zeolite and it is now introduced in the extrudates, were observed. The nanoscale location was similar (Pt deposed in the zeolites also for shaped support), but the macroscale location depended on the Pt loading. For the lowest Pt content, the Pt was mostly deposed in the edges of the extrudate instead of uniformly distributed.

In hexadecane hydroisomerization, Pt-shaped catalysts revealed similar catalytic features to $\mathrm{Pt} /$ zeolite catalysts, including comparable turnover frequency per protonic site, for high metal to acid sites ratio. These results corroborated the full preservation of zeolite properties. In contrast, 
a reduction in the feed isomers selectivity, comparing to $\mathrm{Pt} /$ zeolite, was disclosed for shaped catalysts with similar metal to acid sites ratio but poor macroscopic distribution of Pt. As the diffusion of intermediates throughout the whole catalyst is much slower than the reaction rate, the catalyst behaves as a mechanical mixture of catalysts holding different metal to acid sites ratio. This leads, at the same overall metal to acid sites ratio, to a lower feed isomers yield. Therefore, the behaviour of a shaped bifunctional catalyst depends not only on the overall metal to acid sites ratio but also on the local metal to acid sites ratios, which are only equal to the bulk one if the metal is homogeneously distributed throughout the shaped body.

In summary, the shaping of zeolites can be achieved with a full conservation of zeolite properties according to procedure herein. In such way, the development or modification of zeolites is fully reproduced in the industrial catalysts. Nevertheless, the repercussions of the scale-up from powder to shaped bodies are not restrained to the properties of the zeolite. An optimal catalytic behaviour can only be ensured by achieving an adequate balance between catalytic functions at the microscale.

\section{Acknowledgements}

Authors would like to thank to M. Moscovici-Mirande, V. Delattre and C. James for the work on $\mathrm{n}-\mathrm{C}_{16}$ hydroisomerization, I. Clemençon and $\mathrm{C}$. Deville for the work with $\mathrm{x}$-ray powder diffraction, A.-L. Taleb and A.-S. Gay for the work on the microscopic techniques, and L. Sorbier for the work on electron microprobe. Financial support was provided by Fundação para a Ciência e Tecnologia through CQE (Project UID/QUI/00100/2013) and PhD grant (SFRH/BD/87927/2012).

\section{References}

[1] A. Primo, H. Garcia, Zeolites as catalysts in oil refining, Chem. Soc. Rev. 43 (2014) 75487561.

[2] Vogt, Eelco T. C., G.T. Whiting, A. Dutta Chowdhury, B.M. Weckhuysen, Zeolites and Zeotypes for Oil and Gas Conversion, in: Friederike C. Jentoft (Ed.), Advances in Catalysis, Academic Press, 2015, pp. 143-314.

[3] F. Bertoncini, A. Bonduelle-Skrzypczak, J. Francis, E. Guillon, Hydrocracking, in: H. Toulhoat, P. Raybaud (Eds.), Catalysis by Transition Metal Sulphides, Ed. Technip, Paris, 2013, pp. 609-677.

[4] J. Weitkamp, Catalytic Hydrocracking-Mechanisms and Versatility of the Process, ChemCatChem 4 (2012) 292-306. 
[5] E. Furimsky, Hydroprocessing challenges in biofuels production, Catal Today 217 (2013) 13-56.

[6] A. Daudin, N. Dupassieux, T. Chapus, Hydrotreatment of Vegetable Oils, in: H. Toulhoat, P. Raybaud (Eds.), Catalysis by Transition Metal Sulphides, Ed. Technip, Paris, 2013, pp. 739-755.

[7] A. Galadima, O. Muraza, Catalytic upgrading of vegetable oils into jet fuels range hydrocarbons using heterogeneous catalysts: A review, Journal of Industrial and Engineering Chemistry 29 (2015) 12-23.

[8] E.F. Sousa-Aguiar, F.B. Noronhac, Faro, Jr., Arnaldo, The main catalytic challenges in GTL (gas-to-liquids) processes, Catal Sci Technol 1 (2011) 698-713.

[9] G. Liu, B. Yan, G. Chen, Technical review on jet fuel production, RENEWABLE \& SUSTAINABLE ENERGY REVIEWS 25 (2013) 59-70.

[10]A.Y. Khodakov, W. Chu, P. Fongarland, Advances in the development of novel cobalt Fischer-Tropsch catalysts for synthesis of long-chain hydrocarbons and clean fuels, Chem. Rev. 107 (2007) 1692-1744.

[11]C. Bouchy, G. Hastoy, E. Guillon, J.A. Martens, Fischer-Tropsch Waxes Upgrading via Hydrocracking and Selective Hydroisomerization, Oil Gas Sci Technol 64 (2009) 91-112.

[12]V.M. Akhmedov, S.H. Al-Khowaiter, Recent advances and future aspects in the selective isomerization of high n-alkanes, Catal Rev 49 (2007) 33-139.

[13]L.B. McCusker, C. Baerlocher, Zeolite structures, in: J. Cejka, H. VanBekkum (Eds.), Zeolites and Ordered Mesoporous Materials: Progress and Prospects, Elsevier Science Bv, Amsterdam, 2005, pp. 41-64.

[14]K.C. Park, S.K. Ihm, Comparison of Pt/zeolite catalysts for n-hexadecane hydroisomerization, Appl Catal a-Gen 203 (2000) 201-209.

[15]A. Gutiérrez, J.M. Arandes, P. Castaño, M. Olazar, J. Bilbao, Preliminary studies on fuel production through LCO hydrocracking on noble-metal supported catalysts, Fuel 94 (2012) 504-515.

[16]J.A. Martens, M. Tielen, P.A. Jacobs, Relation Between Paraffin Isomerisation Capability and Pore Architecture of Large-Pore Bifunctional Zeolites, Stud. Surf. Sci. Catal. 46 49-60. 
[17]W.M. Zhang, P.G. Smirniotis, Effect of zeolite structure and acidity on the product selectivity and reaction mechanism for $n$-octane hydroisomerization and hydrocracking, J. Catal. 182 (1999) 400-416.

[18]P.S.F. Mendes, J.M. Silva, M.F. Ribeiro, P. Duchêne, A. Daudin, C. Bouchy, Quantification of metal-acid balance in hydroisomerization catalysts: a step further towards catalyst design, Aiche J. 63 (2017) 2864-2875.

[19]W. Souverijns, J.A. Martens, G.F. Froment, P.A. Jacobs, Hydrocracking of isoheptadecanes on Pt/H-ZSM-22: An example of pore mouth catalysis, J. Catal. 174 (1998) 177-184.

[20]F.M. Mota, C. Bouchy, E. Guillon, A. Fecant, N. Bats, J.A. Martens, IZM-2: A promising new zeolite for the selective hydroisomerization of long-chain n-alkanes, J. Catal. 301 (2013) 2029.

[21]M. Zhang, Y. Chen, L. Wang, Q. Zhang, C.-W. Tsang, C. Liang, Shape Selectivity in Hydroisomerization of Hexadecane over Pt Supported on 10-Ring Zeolites: ZSM-22, ZSM23, ZSM-35, and ZSM-48, Ind. Eng. Chem. Res. 55 (2016) 6069-6078.

[22]P.S.F. Mendes, F.M. Mota, J.M. Silva, M.F. Ribeiro, A. Daudin, C. Bouchy, A systematic study on mixtures of Pt/zeolite as hydroisomerization catalysts, Catal Sci Technol 7 (2017) 1095-1107.

[23]F. Alvarez, F.R. Ribeiro, G. Perot, C. Thomazeau, M. Guisnet, Hydroisomerization and hydrocracking of alkanes - Influence of the balance between acid and hydrogenating functions on the transformation of n-decane on PtHY catalysts, J. Catal. 162 (1996) 179189.

[24]M. Guisnet, "Ideal" bifunctional catalysis over Pt-acid zeolites, Catal Today 218-219 (2013) 123-134.

[25]P.B. Weisz, Polyfunctional Heterogeneous Catalysis, in: D.D. Eley, P.W. Selwood, Paul B. Weisz, A.A. Balandin, J.H. De Boer, P.J. Debye, P.H. Emmett, J. Horiuti, W. Jost, G. Natta, E.K. Rideal and H.S. Taylor (Ed.), Advances in Catalysis, Academic Press, 1962, pp. 137190.

[26]N. Batalha, L. Pinard, C. Bouchy, E. Guillon, M. Guisnet, n-Hexadecane hydroisomerization over Pt-HBEA catalysts. Quantification and effect of the intimacy between metal and protonic sites, J. Catal. 307 (2013) 122-131.

[27]J. Zecevic, G. Vanbutsele, de Jong, Krijn P., J.A. Martens, Nanoscale intimacy in bifunctional catalysts for selective conversion of hydrocarbons, Nature 528 (2015) 245-248. 
[28]E.F. Gallei, M. Hesse, E. Schwab, Development of Industrial Catalysts, in: G. Ertl, H. Knözinger, F. Schüth, J. Weitkamp (Eds.), Handbook of Heterogeneous Catalysis, WileyVCH Verlag GmbH \& Co. KGaA, Weinheim, Germany, 2008, pp. 57-66.

[29]F. Schüth, M. Hesse, Catalyst Forming, in: G. Ertl, H. Knözinger, F. Schüth, J. Weitkamp (Eds.), Handbook of Heterogeneous Catalysis, Wiley-VCH Verlag GmbH \& Co. KGaA, Weinheim, Germany, 2008.

[30]R.L. Bedard, Synthesis of Zeolites and Manufacture of Zeolitic Catalysts and Adsorbents, in: S. Kulprathipanja (Ed.), Zeolites in Industrial Separation and Catalysis, Wiley-VCH Verlag GmbH \& Co. KGaA, Weinheim, Germany, 2010, pp. 61-83.

[31]S. Mitchell, N.-L. Michels, J. Perez-Ramirez, From powder to technical body: the undervalued science of catalyst scale up, Chem. Soc. Rev. 42 (2013) 6094-6112.

[32]A. Martin, H. Berndt, Neutralization of HZSM-5 Brönsted acid sites by shaping with boehmite, React Kinet Catal Lett 52 (1994) 405-411.

[33]A. Martin, H. Berndt, U. Lohse, U. Wolf, Effect of Si: Al ratio and type of binder on the catalytic properties of HZSM-5 catalysts, J. Chem. Soc., Faraday Trans. 89 (1993) 12771282.

[34]N.-L. Michels, S. Mitchell, J. Pérez-Ramírez, Effects of Binders on the Performance of Shaped Hierarchical MFI Zeolites in Methanol-to-Hydrocarbons, ACS Catal. 4 (2014) 24092417.

[35]A. de Lucas, P. Sánchez, A. Fúnez, M.J. Ramos, J.L. Valverde, Liquid-Phase Hydroisomerization of $\mathrm{n}$-Octane over Platinum-Containing Zeolite-Based Catalysts with and without Binder, Ind. Eng. Chem. Res. 45 (2006) 8852-8859.

[36]K.-Y. Lee, H.-K. Lee, S.-K. Ihm, Influence of Catalyst Binders on the Acidity and Catalytic Performance of HZSM-5 Zeolites for Methanol-to-Propylene (MTP) Process: Single and Binary Binder System, Top Catal 53 (2010) 247-253.

[37]X. Du, X. Kong, L. Chen, Influence of binder on catalytic performance of Ni/HZSM-5 for hydrodeoxygenation of cyclohexanone, Catalysis Communications 45 (2014) 109-113.

[38]K. Ito, H. Jang, K. Sakashita, S. Asaoka, Catalysis at the interface of nano-oxides and nanozeolites, Pure and Applied Chemistry 80 (2008). 
[39]G.T. Whiting, A.D. Chowdhury, R. Oord, P. Paalanen, B.M. Weckhuysen, The curious case of zeolite-clay/binder interactions and their consequences for catalyst preparation, FARADAY DISCUSSIONS 188 (2016) 369-386.

[40]A. de Lucas, P. Sanchez, F. Dorado, M.J. Ramos, J.L. Valverde, Effect of the metal loading in the hydroisomerization of n-octane over beta agglomerated zeolite based catalysts, Appl Catal a-Gen 294 (2005) 215-225.

[41]L. Gueudré, M. Milina, S. Mitchell, J. Pérez-Ramírez, Superior Mass Transfer Properties of Technical Zeolite Bodies with Hierarchical Porosity, Adv. Funct. Mater. 24 (2014) 209-219.

[42]G. Leofanti, M. Padovan, G. Tozzola, B. Venturelli, Surface area and pore texture of catalysts, Catal Today 41 (1998) 207-219.

[43]H. Giesche, Mercury Porosimetry: A General (Practical) Overview, Particle \& Particle Systems Characterization 23 (2006) 9-19.

[44]C.H. Bartholemew, $\mathrm{H} 2$ adsorption on supported noble metals and its use in determining metal dispersion, in: J.J. Spivey, S.K. Agarwal (Eds.), Catalysis: Volume 11, The Royal Society of Chemistry, 1994, pp. 93-126.

[45]J. Prasad, K.R. Murthy, P.G. Menon, Stoichiometry of Hydrogen-Oxygen Titrations on Supported Platinum Catalysts, J. Catal. 52 (1978) 515-520.

[46]P.S.F. Mendes, A.-L. Taleb, A.-S. Gay, A. Daudin, C. Bouchy, J.M. Silva, M.F. Ribeiro, Nanoscale insights into Pt-impregnated mixtures of zeolites, J. Mater. Chem. A 5 (2017) 16822-16833.

[47]S. Kasztelan, N. Marchal-Georges, T. Cseri, P. Leyrit, P. Dascotte, E. Rosenberg, WO 01/00321 A1.

[48]L. Sorbier, E. Rosenberg, C. Merlet, Microanalysis of porous materials, MICROSCOPY AND MICROANALYSIS 10 (2004) 745-752.

[49]L. Sorbier, F. Bazer-Bachi, Y. Blouet, M. Moreaud, V. Moizan-Basle, Use of the Distance Transform for Integration of Local Measurements: Principle and Application in Chemical Engineering, MICROSCOPY AND MICROANALYSIS 22 (2016) 422-431.

[50]L. Sorbier, Determining the Distribution of Metal by Electron Probe Micro Analysis, in: $\mathrm{H}$. Toulhoat, P. Raybaud (Eds.), Catalysis by Transition Metal Sulphides, Ed. Technip, Paris, 2013, pp. 407-411. 
[51]Mendes, Pedro S. F., G. Lapisardi, C. Bouchy, M. Rivallan, J.M. Silva, M.F. Ribeiro, Hydrogenating activity of $\mathrm{Pt} /$ zeolite catalysts focusing acid support and metal dispersion influence, Applied Catalysis A: General 504 (2015) 17-28.

[52]F.M. Mota, C. Bouchy, P. Duchene, J. Martens, High-throughput experimentation for the discovery of new hydroconversion catalysts, Prepr Pap-Am Chem Soc, Div Pet Chem. 243 (2012).

[53]W. Lutz, Zeolite Y: Synthesis, Modification, and Properties-A Case Revisited, Advances in Materials Science and Engineering 2014 (2014) 1-20.

[54]C. Baerlocher, L.B. McCusker, D.H. Olson, Atlas of Zeolite Framework Types, 6th ed., 2007.

[55]K. Wefers, C. Misra, Oxides and hydroxides of aluminum (1987).

[56]N.-L. Michels, S. Mitchell, M. Milina, K. Kunze, F. Krumeich, F. Marone, M. Erdmann, N. Marti, J. Pérez-Ramírez, Hierarchically Structured Zeolite Bodies: Assembling Micro-, Meso, and Macroporosity Levels in Complex Materials with Enhanced Properties, Adv. Funct. Mater. 22 (2012) 2509-2518.

[57]J.A. Lercher, C. Gründling, G. Eder-Mirth, Infrared studies of the surface acidity of oxides and zeolites using adsorbed probe molecules, Catal Today 27 (1996) 353-376.

[58]S. Morin, P. Ayrault, N.S. Gnep, M. Guisnet, Influence of the framework composition of commerical HFAU zeolites on their activity and selectivity in $\mathrm{m}$-xylene transformation, Applied Catalysis A: General 166 (1998) 281-292.

[59]M.R. Guisnet, Model Reactions for Characterizing the Acidity of Solid Catalysts, Accounts Chem Res 23 (1990) 392-398.

[60]F. Ribeiro, C. Marcilly, Étude de la technique d'échange ionique avec compétition. Cas du dépôt de platine sur support solide acide par échange cationique, Rev. Inst. Fr. Pét. 34 (1979) 405-428.

[61]V. Calemma, S. Peratello, C. Perego, Hydroisomerization and hydrocracking of long chain n-alkanes on Pt/amorphous SiO2-Al2O3 catalyst, Appl Catal a-Gen 190 (2000) 207-218.

[62]M.J. Girgis, Y.P. Tsao, Impact of catalyst metal acid balance in $\mathrm{n}$-hexadecane hydroisomerization and hydrocracking, Ind. Eng. Chem. Res. 35 (1996) 386-396.

[63]M. Steijns, G. Froment, P. Jacobs, J. Uytterhoeven, J. Weitkamp, Hydroisomerization and Hydrocracking. 2. Product Distributions from $n$-Decane and $n$-Dodecane, Industrial \& Engineering Chemistry Product Research and Development 20 (1981) 654-660. 
[64]J.W. Thybaut, Narasimhan, C. S. L., J.F. Denayer, G.V. Baron, P.A. Jacobs, J.A. Martens, G.B. Marin, Acid-metal balance of a hydrocracking catalyst: Ideal versus nonideal behavior, Ind. Eng. Chem. Res. 44 (2005) 5159-5169.

[65]H.L. Coonradt, W.E. Garwood, Mechanism of hydrocracking - reactions of paraffins + olefins, Ind Eng Chem Proc Dd 3 (1964) p. 38.

[66]F.R. Ribeiro, F. Alvarez, M. Guisnet, C. Marcilly, Influence of the macroscopic distribution of platinum in PtHFAU catalysts on their activity for $n$-hexane isomerization, React Kinet Catal Lett 77 (2002) 301-308. 